\title{
Platform for High-Spin Molecules: A Verdazyl-Nitronyl Nitroxide Triradical with Quartet Ground State
}

Evgeny V. Tretyakov, ${ }^{*}{ }^{\S}$ Pavel V. Petunin, ${ }^{*}{ }^{\dagger}$ Svetlana I. Zhivetyeva, ${ }^{\star}$ Dmitry E. Gorbunov, ${ }^{\perp}$ Nina P. Gritsan, ${ }^{\perp}$ Matvey V. Fedin, ${ }^{\diamond}$ Dmitri V. Stass $,{ }^{\perp},{ }^{\circ}$ Rimma I. Samoilova,${ }^{\perp}$ Irina Yu. Bagryanskaya, ${ }^{\ddagger}$ Artem S. Bogomyakov, ${ }^{\diamond}$ Maxim S. Kazantsev, ${ }^{\ddagger}$ Pavel S. Postnikov, ${ }^{\dagger}$ Marina E. Trusova, ${ }^{\dagger}$ and Victor I. Ovcharenko*,

${ }^{\S}$ N.D. Zelinsky Institute of Organic Chemistry, Russian Academy of Sciences, Leninsky Ave. 47, Moscow 119991, Russian Federation

${ }^{\dagger}$ Tomsk Polytechnic University, Lenin Ave. 30, Tomsk 634050, Russian Federation

$\$$ N.N. Vorozhtsov Novosibirsk Institute of Organic Chemistry, Siberian Branch of Russian Academy of Sciences, Ac. Lavrentiev Ave. 9, Novosibirsk 630090, Russian Federation

$\perp$ V.V. Voevodsky Institute of Chemical Kinetics and Combustion, Siberian Branch of Russian Academy of Sciences, Institutskaya Str. 3, Novosibirsk 630090, Russian Federation

${ }^{\diamond}$ International Tomography Center, Siberian Branch of Russian Academy of Sciences, Institutskaya Str. 3a, Novosibirsk 630090, Russian Federation

${ }^{\square}$ Novosibirsk State University, Pirogova Str. 2, Novosibirsk 630090, Russian Federation

ABSTRACT: Thermally resistant air-stable organic triradicals with a quartet ground state and a large energy gap between spin states are still unique compounds. Moreover, stable triradicals with bridging units of the ethylene-1,1-diyl type and ferromagnetic coupling are limited to the family of nitroxides. In this work, for the first time, we designed and prepared the triradical having a quartet ground state based on oxoverdazyl and nitronyl nitroxide radical fragments. The triradical and appropriate triplet diradical precursor were synthesized via a palladium-catalyzed cross-coupling reaction of diiodoverdazyl with nitronyl nitroxide-2-ide gold(I) complex. Both the di- and triradical are air-stable and possess good thermal stability with decomposition onset at $\sim 160{ }^{\circ} \mathrm{C}$ in an inert atmosphere. X-ray diffraction analysis of single crystals confirmed the presence of verdazyl and nitroxide radical centers. In the diradical, the verdazyl and nitronyl nitroxide centers showed fully reversible redox waves. In case of the triradical, the electrochemical processes occur practically at the same redox potentials but become quasi-reversible for the nitroxide moieties. Magnetic properties of the di- and triradical were characterized by a SQUID magnetometry of polycrystalline powders and by EPR spectroscopy in different matrices. Collected data analyzed using of the highlevel quantum chemical calculations confirmed that the di- and triradical have high-spin ground 
states. Unique high stability of prepared verdazyl-nitronylnitroxyl triradical opens new perspectives for further functionalization and design of high-spin systems with four or more spins.

\section{INTRODUCTION}

$\pi$-Conjugated purely organic high-spin molecules (di- and polyradicals) with substantial intramolecular exchange interactions and intriguing magnetic properties have a significant potential for advanced technological applications and fundamental science. ${ }^{1,2,3,4,5}$ The stable di- and polyradicals are considered as working elements of spintronic devices, ${ }^{6,7,8}$ multifunctional molecule-based magnetic materials, and quantum machines. ${ }^{9,10}$ Guidelines for the design of such high-spin molecules with exchange-coupled stable radical moieties have been developed using MO $11,12,13,14,15$ and $\mathrm{VB}^{16,17}$ theories. Based on these recommendations, a number of diradicals with $m$ phenylene or alkylidene bridging units with strong ferromagnetic interaction between radical parts and with room temperature stability have been designed. ${ }^{18,19,20,21,22,23,24,25,26}$ Despite the obvious breakthrough in the chemistry of diradicals with a large energy gap between the high-spin ground state and low-spin excited state, air-stable tri- and polyradicals are still exotic compounds.

Previously reported examples of thoroughly characterized organic triradicals with a quartet ground state are shown in Figure 1. Polychlorinated triradical $\mathbf{1}$ is the only one representative of carbon-based triradical, where chlorine atoms prevent dimerization and restrict rotation of aryl groups owing to steric hindrance. ${ }^{27}$ Triradical 1 is stable in air up to $250{ }^{\circ} \mathrm{C}$; it was isolated as two stereoisomers with $C_{2}$ and $D_{3}$ symmetries. Magnetic measurements have revealed that the energy gap between the quartet ground state and the lowest energy doublet state $\left(\Delta E_{\mathrm{DQ}} / \mathrm{k}\right)$ exceeds $290 \mathrm{~K}$ for both forms. Among annulated hydrazyls, 1,3,5-trisverdazyl-benzene (2) has been prepared as black prisms decomposing at $242-243^{\circ} \mathrm{C} .{ }^{28}$ It has been shown that the quartet and doublet states of triradical 2 are equally populated in the temperature range from 230 to $340 \mathrm{~K}$.

The greatest success in the synthesis of triradicals with a quartet ground state has been achieved for nitroxides, which can be purified by column chromatography and applied as well-defined highspin units for metal complexation. ${ }^{29,30}$ In crystals of the first nitronyl nitroxide (NN) triradical 3 (ref. 31; Figure 1), intramolecular exchange interactions have been overlapped with intermolecular antiferromagnetic interactions. To estimate the intramolecular magnetic coupling, a mixed crystal of 3 with 1,3,5-trinitrobenzene $(\mathbf{3} \cdot \mathrm{TNB}, 1: 1)$ was prepared. Superconducting quantum interference device (SQUID) magnetometry of $\mathbf{3} \cdot \mathrm{TNB}$ has proved the intramolecular ferromagnetic interactions with $J / k_{\mathrm{B}}=23 \mathrm{~K} \cdot{ }^{32,33,34}$ The intramolecular ferromagnetic coupling is quite weak due to the small spin population of the $\mathrm{C}(2)$ atom in the NN part. Similar weak intramolecular exchange interactions with $J / k_{\mathrm{B}}=6.8-15.3 \mathrm{~K}$ have been observed in tert-butyl nitroxide triradicals 4 and $\mathbf{5} .^{35,36,37}$ The shortening of linkers between the paramagnetic centers has led to a significant increase in the 
exchange interaction parameters. Thus, in triradical 6, the energy gap between the quartet ground and the lowest excited doublet states is reported to be $240 \mathrm{~K} \cdot{ }^{38}$ Finally, the magnetic measurements of mixed triradicals 7 and $\mathbf{8}$ have clearly proved quartet ground states with $J / k_{\mathrm{B}}=231$ and $127 \mathrm{~K}$, respectively. ${ }^{19}$
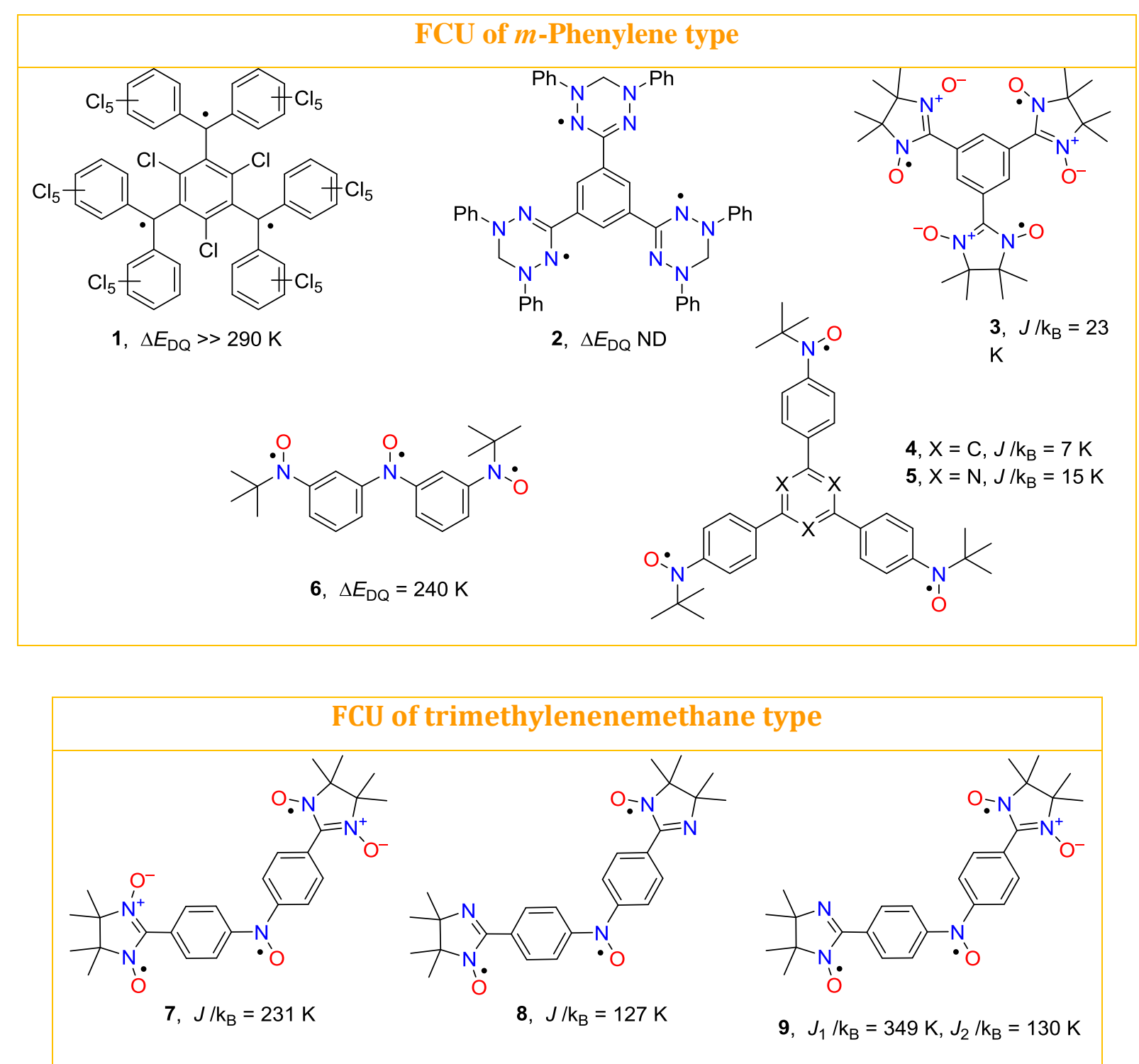

Figure 1. Previously reported air-stable organic triradicals with a quartet ground state.

In the current work, we present a new type of triradical (NN-Vrd-NN, Figure 2) as a verdazyl (Vrd)-containing analog of compound 7 (Figure 1). Replacing the nitroxide moiety with Vrd is justified due to higher stability and a great potential for structure modification. In addition to the obvious possibility of conversion of an $\mathrm{NN}$ group into an iminonitroxide one, the NN-Vrd-NN triradical contains one more phenyl substituent suitable for functional groups addition including paramagnetic centers. This property allows us to regard the NN-Vrd-NN triradical as a platform for the design of high-spin polyradicals. To create such molecules, it is important to investigate intramolecular exchange interactions in NN-Vrd-NN for future research. 


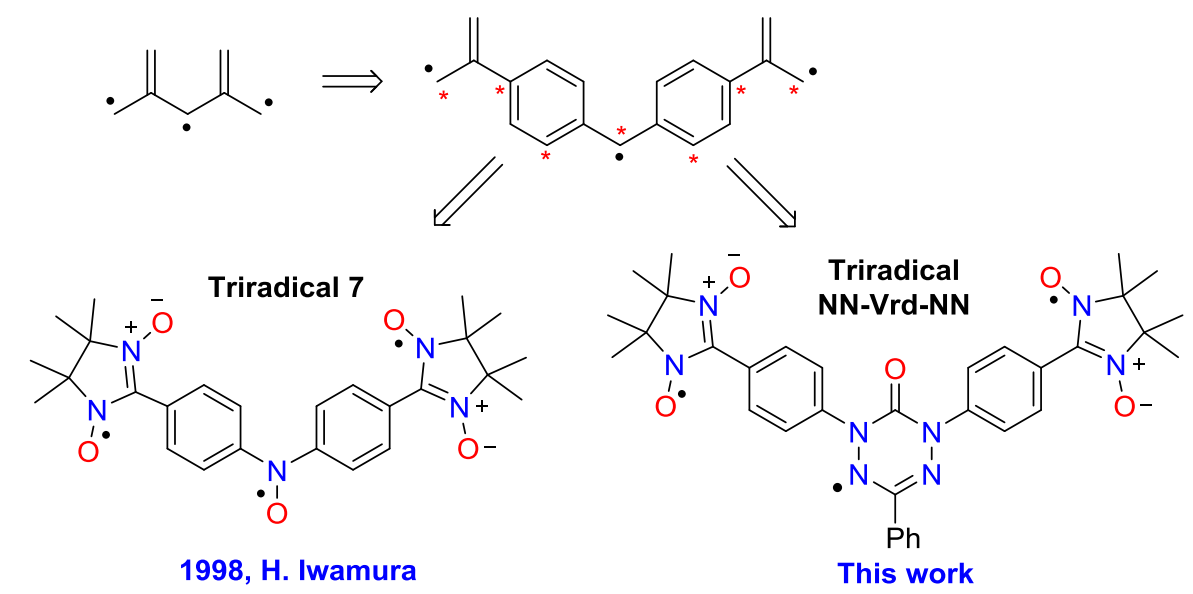

Figure 2. Step-by-step design of triradicals 7 and NN-Vrd-NN using ethylene-1,1-diyls as coupling units.

Here, we report the synthesis, molecular and crystal structure, and magnetic properties of airstable triradical NN-Vrd-NN and its diradical precursor I-Vrd-NN. Analysis of temperature dependence of magnetic susceptibility and pulse EPR-detected transient nutations confirmed the triplet and quartet ground states of the diradical and triradical, respectively.

\section{RESULTS AND DISCUSSION}

Our approach to the synthesis of triradical NN-Vrd-NN is related to the previously reported pathway for diradical Vrd-NN with a triplet ground state, proving the high stability of 6oxoverdazyls in reaction conditions. ${ }^{26}$ Diradical I-Vrd-NN and triradical NN-Vrd-NN were prepared by a palladium-catalyzed cross-coupling reaction of novel diiodoverdazyl I-Vrd-I with a gold(I) nitronyl nitroxide-2-ide complex $\mathrm{Ph}_{3} \mathrm{P}-\mathrm{Au}-\mathrm{NN}^{39,40}$ (Scheme 1, Experimental Section and Supporting Information Section S1).

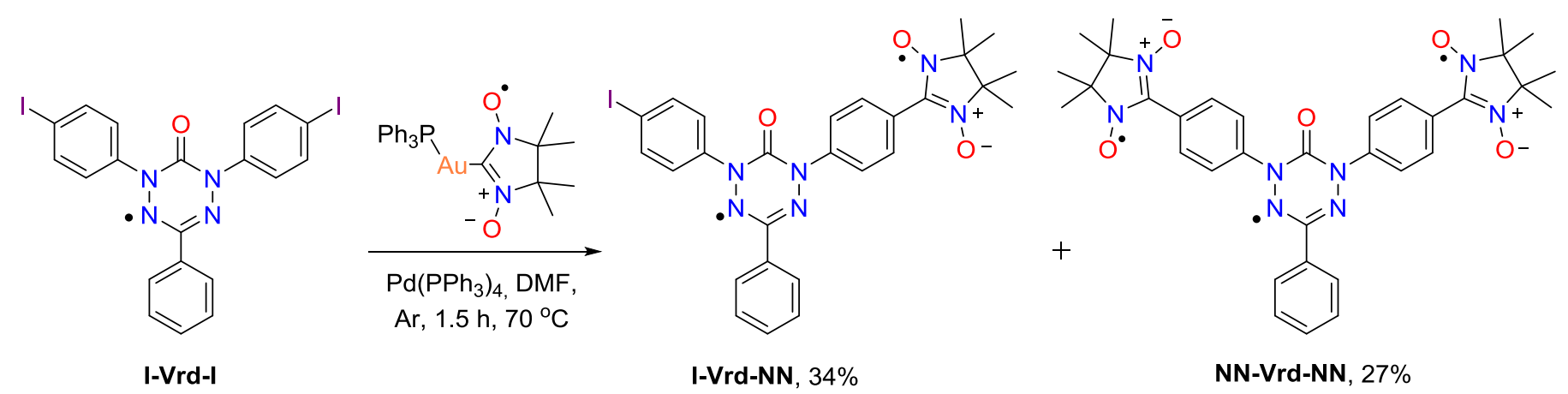

Scheme 1. Synthesis of diradical I-Vrd-NN and triradical NN-Vrd-NN. 
Mixtures of I-Vrd-NN and NN-Vrd-NN were formed in all experiments and the best result was achieved under the heating of diiodoverdazyl I-Vrd-I (1 eq.) and $\mathrm{Ph}_{3} \mathrm{P}-\mathrm{Au}-\mathrm{NN}$ (1.5 eq.) with $10 \mathrm{~mol} \%$ of $\mathrm{Pd}\left(\mathrm{PPh}_{3}\right)_{4}$ in dimethylformamide (DMF) in an inert atmosphere. Analytically pure samples of the di- and triradical were isolated by column chromatography on silica followed by recrystallization from an $n$-heptane-acetone mixture. This system was also applied for crystal growth.

Crystal structures of I-Vrd-NN and NN-Vrd-NN were solved by X-ray crystallographic analysis. ORTEP drawings with a numbering scheme of both paramagnets are given in Figure 3; the selected bond distances and angles with their estimated standard deviations are listed in Table 1.

(a)

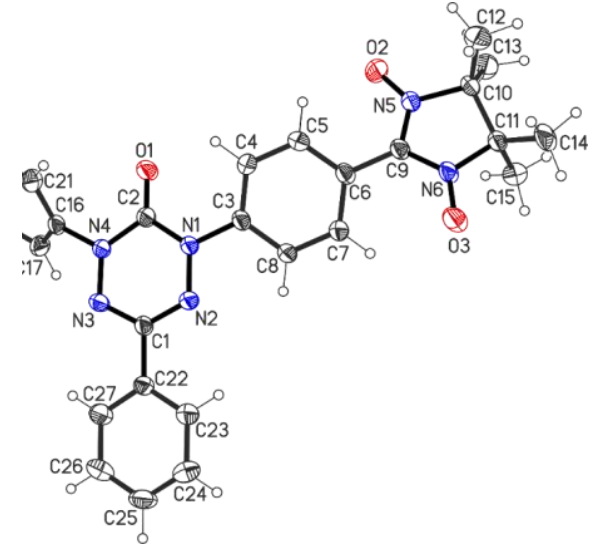

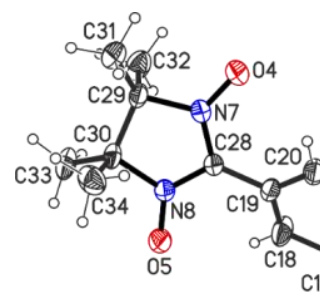

(b)

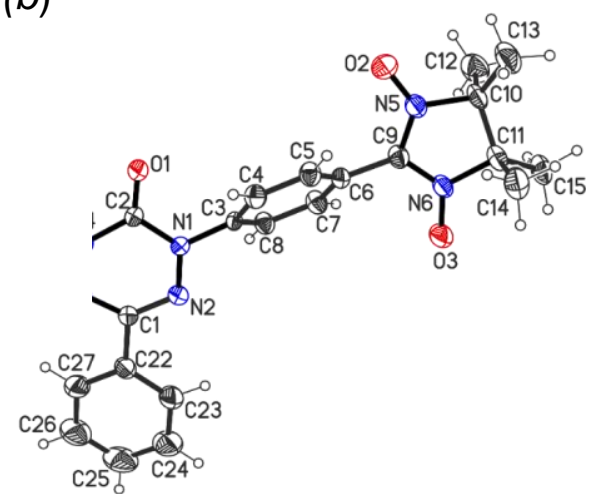

Figure 3. ORTEP views of diradical I-Vrd-NN and triradical NN-Vrd-NN (thermal ellipsoids are drawn at the $50 \%$ probability level).

Table 1. Selected Bond Distances $(\AA)$ and Angles (deg) for I-Vrd-NN and triradical NN-Vrd-NN

\begin{tabular}{|c|c|c|c|}
\hline \multicolumn{2}{|c|}{ I-Vrd-NN } & \multicolumn{2}{|c|}{ NN-Vrd-NN } \\
\hline \multicolumn{4}{|c|}{ Bond Distances $(\AA)$} \\
\hline $\mathrm{I}(1)-\mathrm{C}(19)$ & $2.096(2)$ & $\mathrm{O}(1)-\mathrm{C}(2)$ & $1.212(3)$ \\
\hline $\mathrm{O}(1)-\mathrm{C}(2)$ & $1.205(3)$ & $\mathrm{O}(2)-\mathrm{N}(5)$ & $1.281(3)$ \\
\hline $\mathrm{O}(2)-\mathrm{N}(5)$ & $1.285(3)$ & $\mathrm{O}(3)-\mathrm{N}(6)$ & $1.289(3)$ \\
\hline $\mathrm{O}(3)-\mathrm{N}(6)$ & $1.283(3)$ & $\mathrm{O}(4)-\mathrm{N}(7)$ & $1.288(3)$ \\
\hline $\mathrm{N}(1)-\mathrm{N}(2)$ & $1.368(4)$ & $\mathrm{O}(5)-\mathrm{N}(8)$ & $1.289(3)$ \\
\hline $\mathrm{N}(1)-\mathrm{C}(2)$ & $1.397(3)$ & $\mathrm{N}(1)-\mathrm{N}(2)$ & $1.378(3)$ \\
\hline $\mathrm{N}(2)-\mathrm{C}(1)$ & $1.329(3)$ & $\mathrm{N}(1)-\mathrm{C}(2)$ & $1.390(3)$ \\
\hline $\mathrm{N}(3)-\mathrm{N}(4)$ & $1.361(4)$ & $\mathrm{N}(2)-\mathrm{C}(1)$ & $1.340(3)$ \\
\hline $\mathrm{N}(3)-\mathrm{C}(1)$ & $1.336(3)$ & $\mathrm{N}(3)-\mathrm{N}(4)$ & $1.372(3)$ \\
\hline $\mathrm{N}(4)-\mathrm{C}(2)$ & $1.388(3)$ & $\mathrm{N}(3)-\mathrm{C}(1)$ & $1.327(3)$ \\
\hline $\mathrm{N}(5)-\mathrm{C}(9)$ & $1.348(3)$ & $\mathrm{N}(4)-\mathrm{C}(2)$ & $1.393(3)$ \\
\hline $\mathrm{N}(6)-\mathrm{C}(9)$ & $1.347(3)$ & $\mathrm{N}(5)-\mathrm{C}(9)$ & $1.332(3)$ \\
\hline & & $\mathrm{N}(6)-\mathrm{C}(9)$ & $1.345(3)$ \\
\hline \multicolumn{4}{|c|}{ Bond Angles (deg) } \\
\hline $\mathrm{N}(2)-\mathrm{N}(1)-\mathrm{C}(2)$ & $123.2(2)$ & $\mathrm{N}(2)-\mathrm{N}(1)-\mathrm{C}(2)$ & $125.2(2)$ \\
\hline $\mathrm{N}(1)-\mathrm{N}(2)-\mathrm{C}(1)$ & $116.5(2)$ & $\mathrm{N}(1)-\mathrm{N}(2)-\mathrm{C}(1)$ & $114.2(2)$ \\
\hline $\mathrm{N}(4)-\mathrm{N}(3)-\mathrm{C}(1)$ & $114.3(2)$ & $\mathrm{N}(4)-\mathrm{N}(3)-\mathrm{C}(1)$ & $116.1(2)$ \\
\hline
\end{tabular}

\footnotetext{
* Monoradical precursor I-Vrd-I upon crystallization from various solvents gives tightly intertwined fineneedle crystals. The crystals were too thin, not suitable for single crystal X-ray study.
} 


\begin{tabular}{llll}
$\mathrm{N}(3)-\mathrm{N}(4)-\mathrm{C}(2)$ & $125.7(2)$ & $\mathrm{N}(3)-\mathrm{N}(4)-\mathrm{C}(2)$ & $123.8(2)$ \\
$\mathrm{N}(2)-\mathrm{C}(1)-\mathrm{N}(3)$ & $126.7(2)$ & $\mathrm{N}(2)-\mathrm{C}(1)-\mathrm{N}(3)$ & $127.2(2)$ \\
$\mathrm{N}(1)-\mathrm{C}(2)-\mathrm{N}(4)$ & $113.2(2)$ & $\mathrm{N}(1)-\mathrm{C}(2)-\mathrm{N}(4)$ & $113.5(2)$ \\
$\mathrm{O}(1)-\mathrm{C}(2)-\mathrm{N}(1)$ & $124.5(2)$ & $\mathrm{O}(1)-\mathrm{C}(2)-\mathrm{N}(1)$ & $122.0(2)$ \\
$\mathrm{O}(1)-\mathrm{C}(2)-\mathrm{N}(4)$ & $122.3(2)$ & $\mathrm{O}(1)-\mathrm{C}(2)-\mathrm{N}(4)$ & $124.5(2)$ \\
$\mathrm{O}(2)-\mathrm{N}(5)-\mathrm{C}(9)$ & $126.8(2)$ & $\mathrm{O}(2)-\mathrm{N}(5)-\mathrm{C}(9)$ & $126.4(2)$ \\
$\mathrm{O}(3)-\mathrm{N}(6)-\mathrm{C}(9)$ & $126.2(2)$ & $\mathrm{O}(3)-\mathrm{N}(6)-\mathrm{C}(9)$ & $126.1(2)$ \\
& & $\mathrm{O}(4)-\mathrm{N}(7)-\mathrm{C}(28)$ & $126.3(2)$ \\
& & $\mathrm{O}(5)-\mathrm{N}(8)-\mathrm{C}(28)$ & $126.4(2)$ \\
\hline
\end{tabular}

In crystalline paramagnets I-Vrd-NN and NN-Vrd-NN, bond lengths in the NN and Vrd parts are close to the average values reported for these types of radicals. ${ }^{41,42}$ The Vrd and phenyl rings are nearly planar. The imidazoline rings have a twisted shape (C2 symmetry): in I-Vrd-NN, the C10 and $\mathrm{C} 11$ atoms are located on opposite sides of the plane of the NN moiety at distances of 0.145 and $0.195 \AA$; in NN-Vrd-NN, atoms C10, C11, C29, and C30 are located at distances of 0.220 to 0.284 $\AA$. The NN groups are twisted at different angles $\left(28.3-51.3^{\circ}\right)$ relative to the phenyl rings, as the phenyl rings are twisted in relation to the Vrd ring $\left(6.9^{\circ}\right.$ and $11.5^{\circ}$ for slightly twisted $\mathrm{C} 22-\mathrm{C} 27$ phenyl rings, and from $22.40^{\circ}$ to $53.2^{\circ}$ for the other rings).

The I-Vrd-NN diradical crystallizes as a 1:1 solvate with acetone in the triclinic $P-1$ space group. The crystal packing of the diradical is characterized by short intermolecular contacts O3...H21 (2.533 A) leading to the formation of centrosymmetrical dimers (Figure 4, Table S2.1). Each dimer is linked with two adjacent dimers by short contacts O2...H18 (2.656 $)$ ), thus yielding a ribbon structure. Acetone molecules fill the space between the ribbons occupying a fixed position

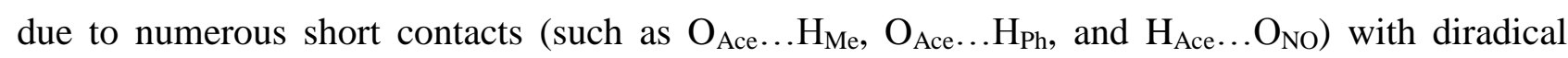
molecules and with neighboring acetone (Figure S2.1).

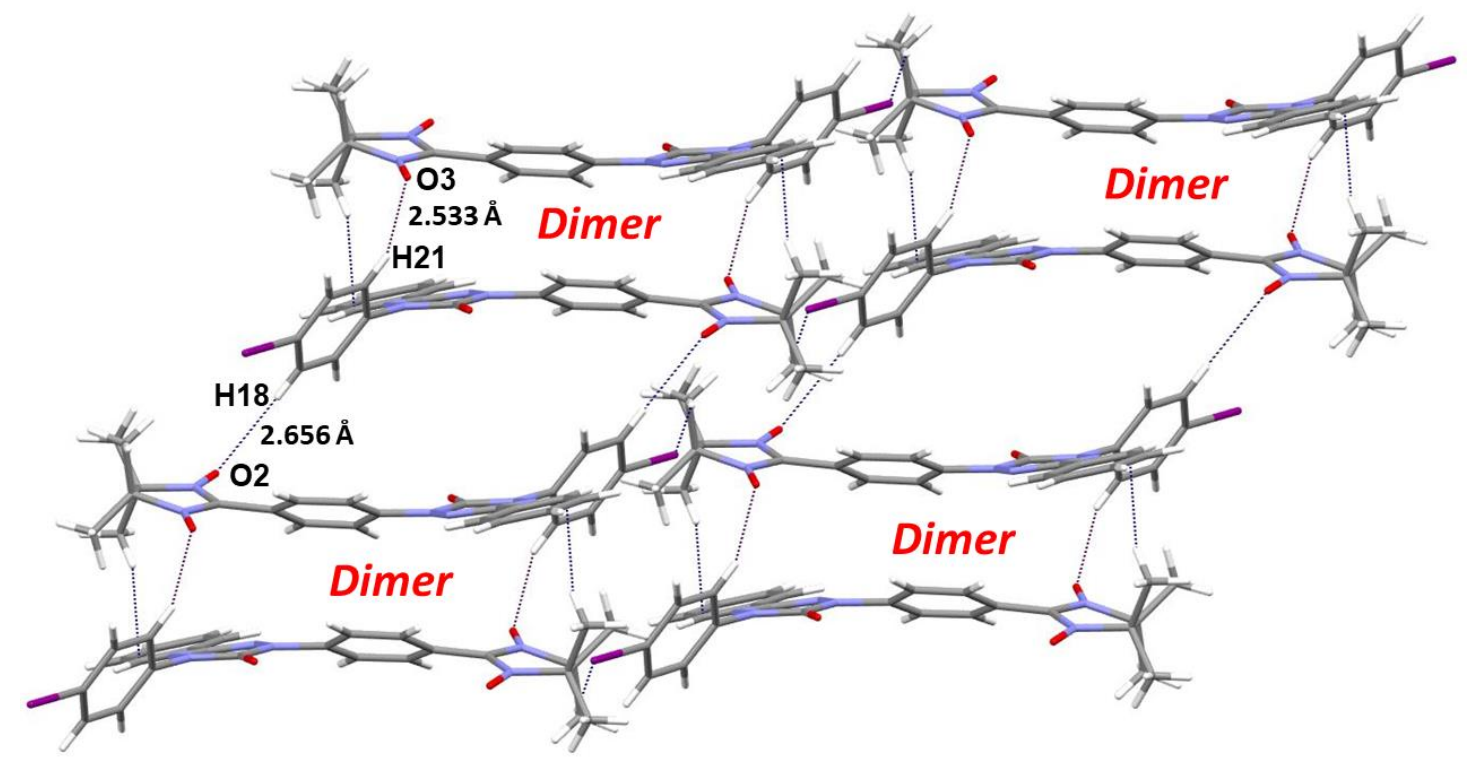

Figure 4. A fragment of the crystal structure showing dimers of diradicals I-Vrd-NN and the packing of dimers into one-dimensional chains; short intermolecular contacts including contacts of oxygen atoms are indicated by dotted lines (acetone molecules are omitted for clarity). 
The NN-Vrd-NN triradical crystallizes in the tetragonal $P 4_{2} /$ n space group where free volume is occupied by highly disordered solvent molecules. In the triradical's crystals, oxygen atoms of one nitroxide group form short intermolecular contacts O3...H13A $(2.540 \AA)$ and O2 ...H7 (2.555 $\AA)$ with hydrogen atoms of one of the methyl groups and phenyl moiety, respectively (Figure 5a, Table S2.1). Such contacts give rise to ribbons in which the oxygen atom of another nitroxide group forms the O5...H31C contact $(2.575 \AA)$. Rotation of the crystal structure of NN-Vrd-NN clearly demonstrated that the ribbon is connected by short O4...H31A contacts (2.448 $\AA$ ) with the neighboring ribbon to form a centrosymmetric fragment (Figure 5b). Finally, the dimeric units are packed due to intermolecular short contacts with the participation of Vrd oxygen atoms O1...H13B,

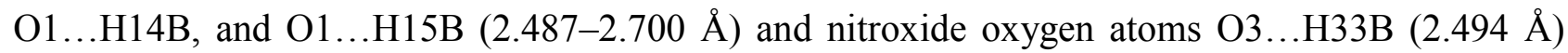
with the formation of a parquet motif (Figure 5c). Another important feature of the crystal structure is the formation of infinite $\pi$-stacks between the $\operatorname{Vrd}$ and phenyl rings (C22-C27): the distances between the molecular planes inside the stacks are $3.55 \AA$ [Cg...Cg 3.573(2) $\AA]$ for I-Vrd-NN and $3.54 \AA[\mathrm{Cg} \ldots \mathrm{Cg} 3.710(2) \AA]$ for NN-Vrd-NN (Figure S2.2)

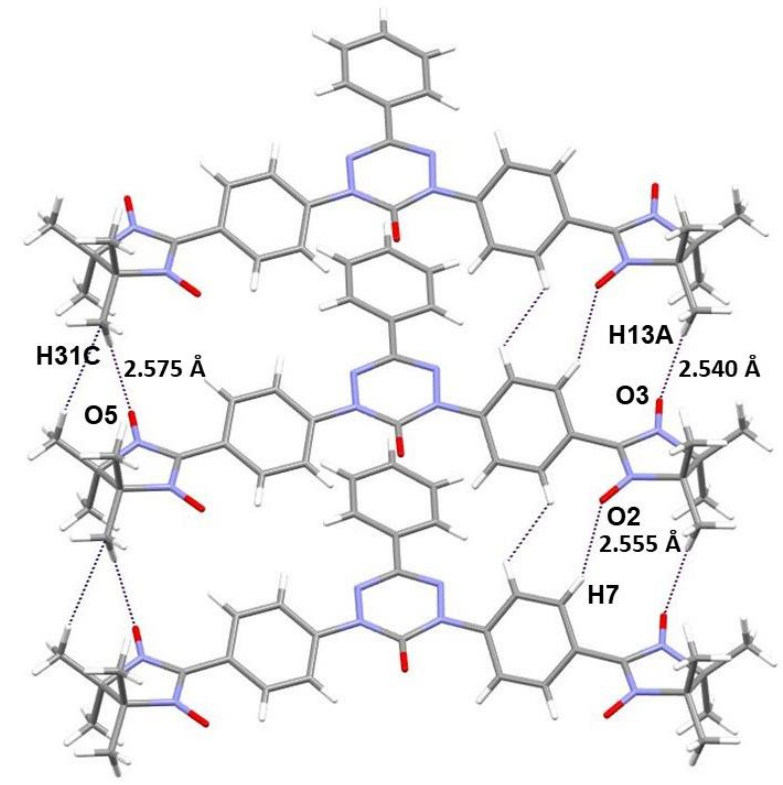



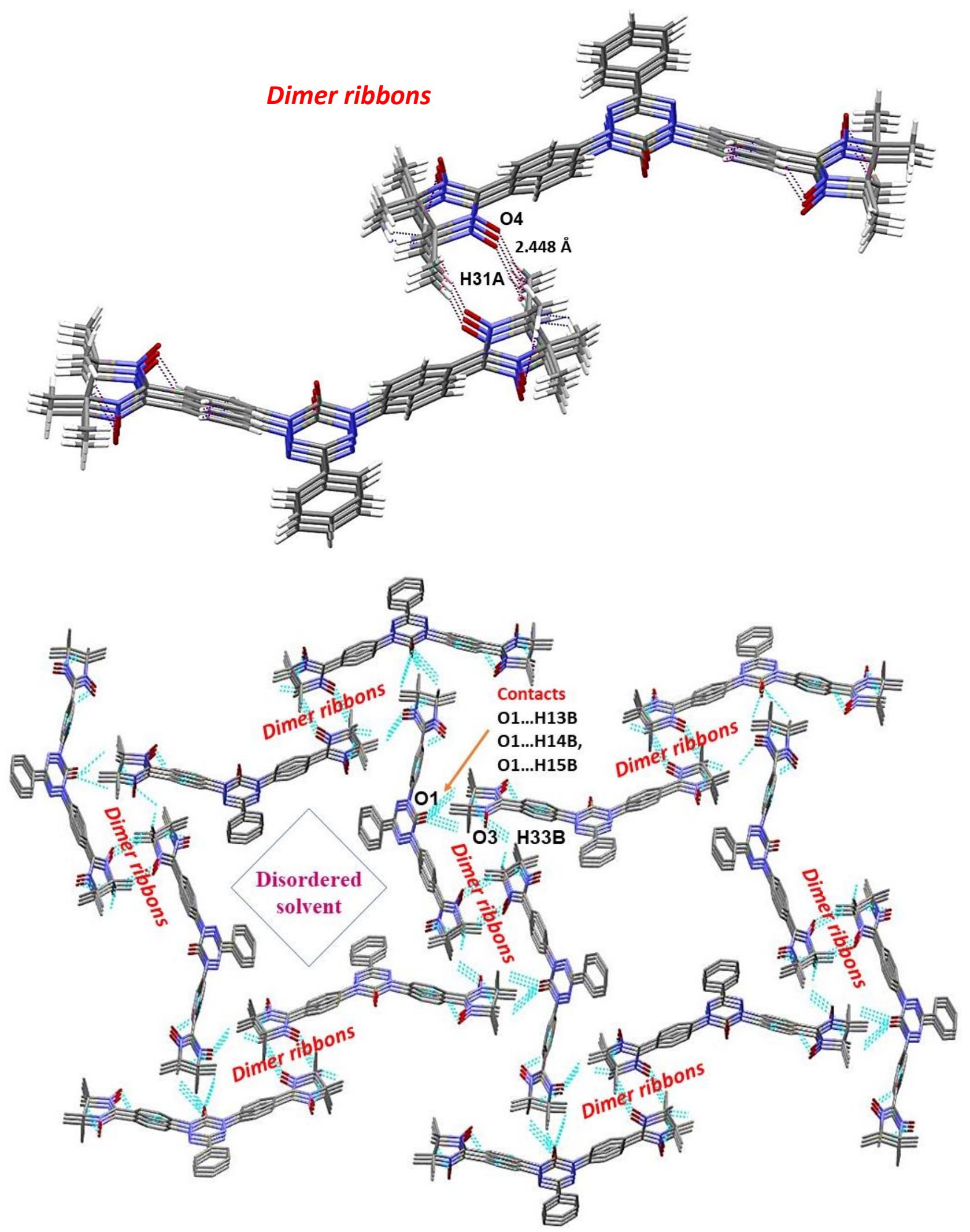

Figure 5. A fragment of the crystal structure showing a ribbon of NN-Vrd-NN triradicals $(a)$, a dimer of ribbons $(b)$, and their packing $(c)$. Short intermolecular contacts, including those of nitroxide oxygens are indicated by dotted lines.

To study the electronic structure of the mono-, di-, and triradical, we used UV-Vis spectroscopy, cyclic voltammetry, and quantum chemical calculations. Analysis of the UV-Vis 
spectra (Figure S3.1, SI Section S3) showed that the long-wavelength bands of all the compounds have similar maxima $(562-576 \mathrm{~nm})$ and intensities. By contrast, the spectra revealed the sufficient differences in the $300-400 \mathrm{~nm}$ region (or $25000-33000 \mathrm{~cm}^{-1}$ ): if we go from Vrd radical I-Vrd-I to the di- and triradical (I-Vrd-NN and NN-Vrd-NN), the broad structureless band of the monoradical was replaced by a band characteristic of NN radicals with vibrational structure. ${ }^{43}$ To assign the absorption bands and to understand similarities and differences between these spectra, we performed time-dependent DFT calculations at the TD-UB3LYP/def2-TZVP level of theory.
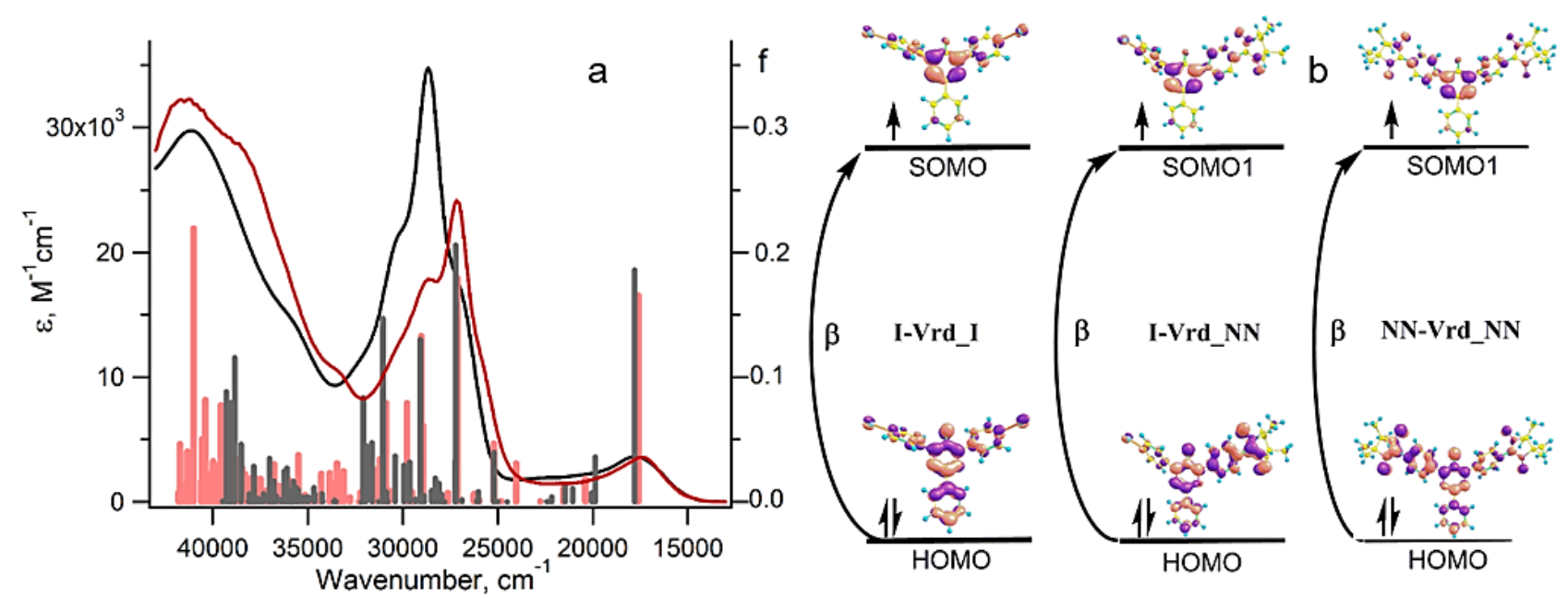

Figure 6. Experimental UV-Vis spectra of the I-Vrd-NN diradical (red) and NN-Vrd-NN triradical (black). The vertical bars indicate positions and oscillator strengths (right axis) of the electronic transitions calculated at the TD-UB3LYP/def2-TZVP level for I-Vrd-NN (red bars) and NN-VrdNN (black bars) $(a)$. The excitations (HOMO $\rightarrow$ SOMO1) that contribute mainly to the longwavelength bands of the I-Vrd-I radical, I-Vrd-NN diradical, and NN-Vrd-NN triradical $(b)$.

The calculations were in good agreement with experimental UV-Vis spectra of I-Vrd-NN and NN-Vrd-NN (Fig. 6a). The long-wavelength transitions triradicals mainly cause a redistribution of the electronic density within the Vrd moiety, similar to the case of the I-Vrd-I radical (Figure 6b).

The observed electrochemical properties also correlate well with theoretical calculations of SOMO energies (SI Section S3, Figure S3.6). According to the calculations, SOMO1 orbitals in all three compounds have similar energies and are localized mainly on Vrd moieties with minor delocalization to other moieties. SOMO2 in I-Vrd-NN, as well as SOMO2 and SOMO3 in NNVrd-NN, are localized exclusively on NN moieties, and their energies are almost identical (Figure S3.6). The arrangement of the orbitals in the energy diagram and the corresponding distributions of the electron density are reflected in the electrochemical properties of paramagnets (Figure 7, Table 2). Electrochemical reduction of the Vrd moiety in the mono-, di-, and triradical in $\mathrm{CH}_{2} \mathrm{Cl}_{2}$ appears as one-electron reversible reduction waves with half-wave potentials of approximately $-0.90 \mathrm{~V}$ 
(versus $\mathrm{Fc} / \mathrm{Fc}^{+}$, hereinafter). Likewise, oxidation processes associated with the Vrd part are characterized by reversible waves with similar half-wave potentials: $+0.52 \mathrm{~V}$ for I-Vrd-I and approximately $+0.40 \mathrm{~V}$ for I-Vrd-NN and NN-Vrd-NN. The observed potentials are typical for radicals of the Vrd family. ${ }^{44}$ The next set of redox waves (approximately -1.46 and $+0.60 \mathrm{~V}$ ) is associated with reduction and oxidation of the NN groups, respectively. It should be noted that redox processes of NN radical are reversible only in diradical I-Vrd-NN and become quasireversible in triradical NN-Vrd-NN.

Table 2. Oxidation and reduction potentials of the mono-, di-, and triradical in $\mathrm{CH}_{2} \mathrm{Cl}_{2}{ }^{a}$

\begin{tabular}{ccccc}
\hline Compound & $E_{\text {Red } 2}^{1 / 2}$ & $E_{\text {Red } 1}^{1 / 2}$ & $E_{\text {Ox1 }}^{1 / 2}$ & $E_{\text {Ox2 }}^{1 / 2}$ \\
\hline I-Vrd-I & - & -0.89 & 0.52 & - \\
I-Vrd-NN & -1.48 & -0.88 & 0.41 & 0.62 \\
NN-Vrd-NN & $-1.45^{b}$ & -0.88 & 0.39 & $0.61^{b}$
\end{tabular}

${ }^{a}$ Potentials are presented in $\mathrm{V} v s \mathrm{Fc} / \mathrm{Fc}^{+} ;{ }^{b}$ quasi-reversible processes.

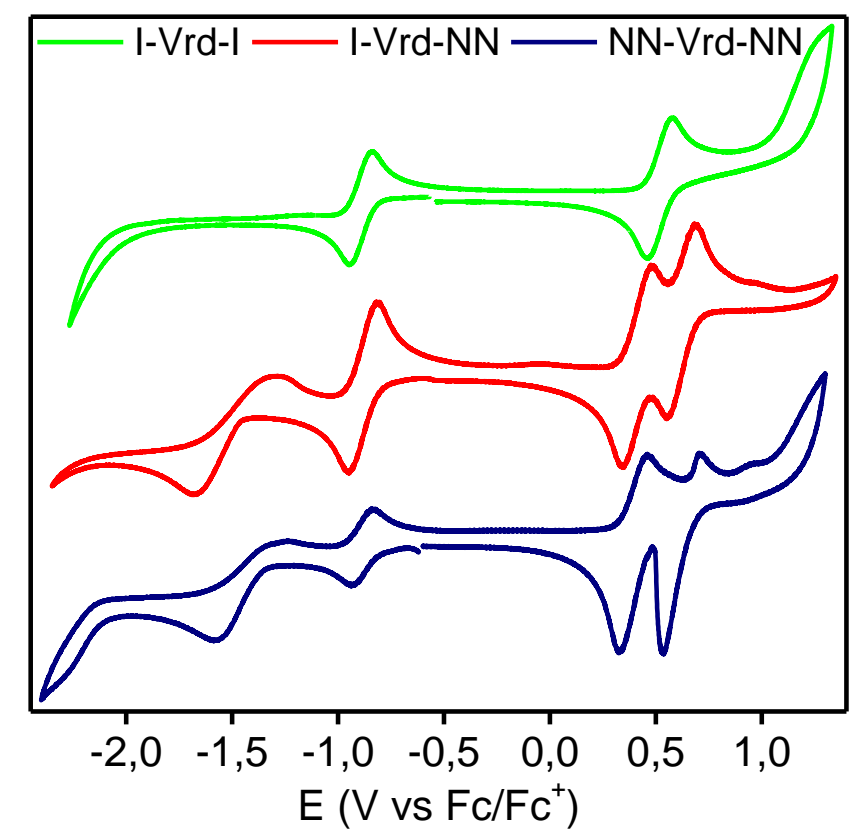

Figure 7. Cyclic voltammograms of the mono-, di-, and triradical in $\mathrm{CH}_{2} \mathrm{Cl}_{2}$ solution $(100 \mathrm{mV} / \mathrm{s}$ with $0.1 \mathrm{M} \mathrm{Bu}_{4} \mathrm{NPF}_{6}$ as an electrolyte).

Figure 8 shows continuous-wave (CW) EPR spectra of I-Vrd-I, I-Vrd-NN, and NN-Vrd-NN recorded in toluene solutions at room temperature. As expected for an increasing number of radical centers per molecule, the EPR spectrum becomes progressively narrower and less resolved (Figure 9a). 

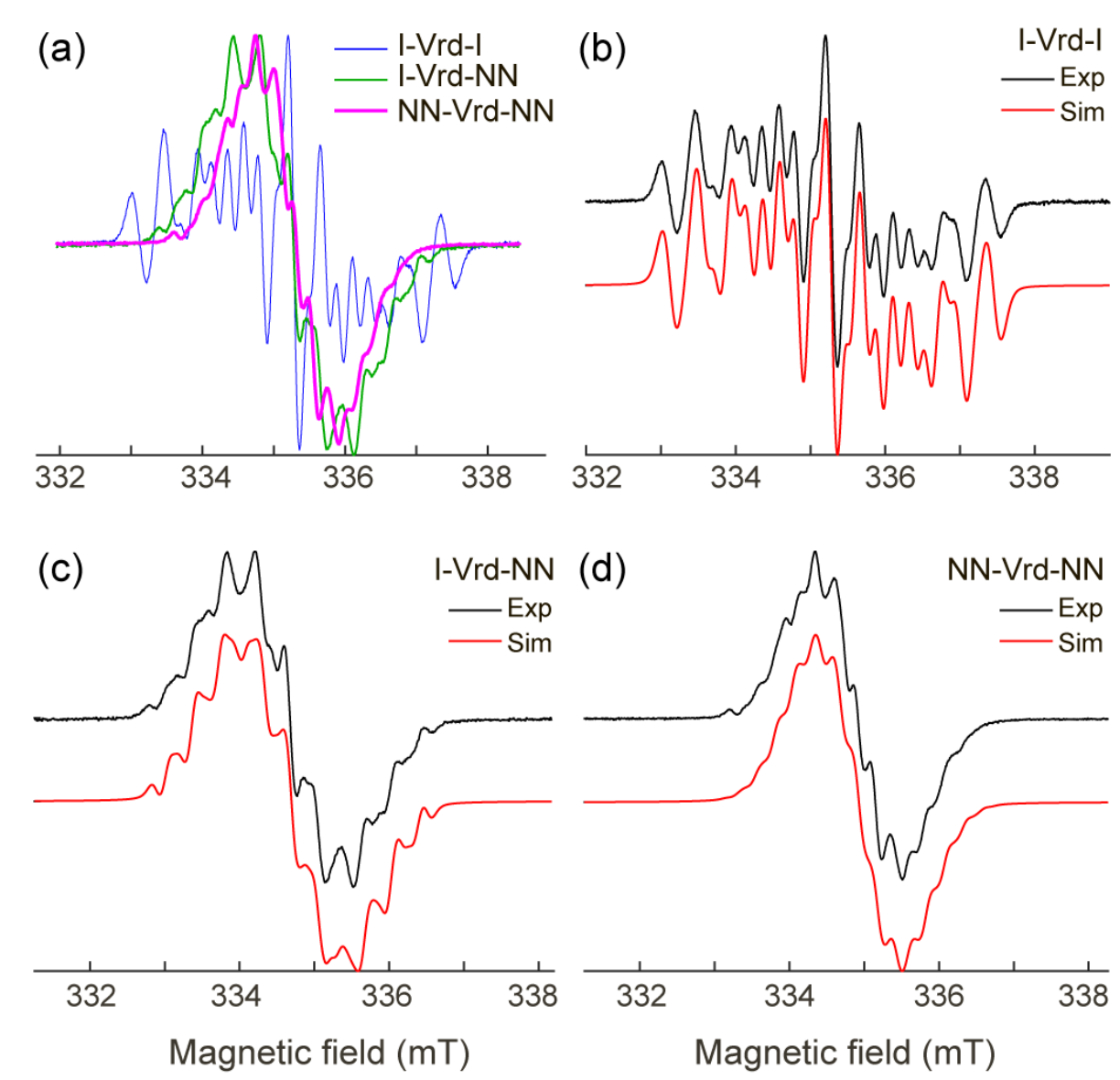

Figure 8. X-band room temperature CW EPR spectra of I-Vrd-I, I-Vrd-NN, and NN-Ver-NN in the toluene solutions. (a) Experimental spectra of all the compounds; (b-d) experimental (black) and simulated (red) spectra of the indicated compounds; parameters of the simulations are given in the text.

The EPR spectrum of the I-Vrd-I monoradical can be well reproduced using four isotropic ${ }^{14} \mathrm{~N}$ hyperfine interaction (HFI) constants $\mathrm{A}_{1}=0.644, \mathrm{~A}_{2}=0.633, \mathrm{~A}_{3}=0.454$, and $\mathrm{A}_{4}=0.427 \mathrm{mT}$ and $\mathrm{g}=2.007$ (Figure 9b). These parameters are in good agreement with the literature data on 6oxoverdazyl radicals. ${ }^{45}$

For a simulation of the EPR spectrum of the I-Vrd-NN diradical, it is necessary to take into account six nitrogen nuclei with six HFI constants. Nonetheless, due to the significant exchange interaction between the two radical centers, each HFI constant must be halved. Thus, the EPR spectrum of I-Vrd-NN can be simulated by means of the constants $\mathrm{A}_{1}-\mathrm{A}_{4}$ obtained above, divided by 2 , as well as the two HFI constants of the NN moiety $\left(\mathrm{A}_{5}=0.726\right.$ and $\left.\mathrm{A}_{6}=0.722 \mathrm{mT}\right)$, also divided by 2 (Figure 8c). The nitrogen atoms of the NN moiety are almost equivalent, and $\mathrm{A}_{5}$ and $\mathrm{A}_{6}$ are very close to the typical values for $\mathrm{NN}$ radicals. ${ }^{46}$ The set of parameters " $\mathrm{A}_{\mathrm{i}}=0.322 ; 0.317$; $0.227 ; 0.213 ; 0.363 ; 0.361 \mathrm{mT}$ (for $\mathrm{i}=1$ to 6 ) and $\mathrm{g}=2.008$ " leads to the best fit.

Similarly, the EPR spectrum of the NN-Vrd-NN triradical can be simulated taking into account eight nitrogen atoms (sum of Vrd and two of NN moieties) and their HFI constants divided by 3 owing to significant exchange interactions among three radical centers. The set of parameters " $\mathrm{A}_{\mathrm{i}}=$ 
$0.215 ; 0.210 ; 0.153 ; 0.143 ; 0.243 ; 0.253 ; 0.249 ; 0.247 \mathrm{mT}$ (for $\mathrm{i}=1$ to 8 ) and $\mathrm{g}=2.0085$ " corresponds to the best fit (Figure 8d). Analysis of all best-fit parameters revealed perfect agreement of the experimental scaling factors with the expected values of 2 and 3 for the di- and triradical, respectively. This is convincing evidence that in liquid solutions synthesized derivatives I-Vrd-NN and NN-Vrd-NN are in the form of a di- and triradical, respectively, and intramolecular exchange interactions are strong (on the EPR scale). Auxiliary pulse EPR experiments in frozen solutions provided additional confirmations of these findings (SI Section S4).

Bulk magnetic properties of the I-Vrd-I radical, I-Vrd-NN diradical, and NN-Vrd-NN triradical were experimentally investigated by SQUID magnetometry of polycrystalline powder samples. In the case of the I-Vrd-I radical, $\chi T$ at $300 \mathrm{~K}$ is close to the theoretical value of $0.375 \mathrm{~cm}^{3} \cdot \mathrm{K} \cdot \mathrm{mol}^{-1}$ for monoradical with $\mathrm{S}=1 / 2$ and $\mathrm{g}_{\text {iso }}=2$. As the temperature decreases from 300 to $50 \mathrm{~K}, \chi T$ remains virtually unchanged, and with further cooling it decreases to $0.119 \mathrm{~cm}^{3} \cdot \mathrm{K} \cdot \mathrm{mol}^{-1}$ at $2 \mathrm{~K}$ (Figure $\mathrm{S} 5.1$.). This simple temperature dependence indicates the presence of weak antiferromagnetic intermolecular exchange interactions. For the I-Vrd-NN diradical, the high-temperature value of $\chi T$ is $0.94 \mathrm{~cm}^{3} \cdot \mathrm{K} \cdot \mathrm{mol}^{-1}$ which is greater than a theoretical one of $0.75 \mathrm{~cm}^{3} \cdot \mathrm{K} \cdot \mathrm{mol}^{-1}$ for two noninteracting spins $\mathrm{S}=1 / 2$ and close to $1.00 \mathrm{emu} \cdot \mathrm{K} \cdot \mathrm{mol}^{-1}$ for one paramagnetic center with spin $\mathrm{S}=1$. With decreasing temperature, $\chi T$ increases reaching $1.00 \mathrm{~cm}^{3} \cdot \mathrm{K} \cdot \mathrm{mol}^{-1}$ at $70 \mathrm{~K}$, and then decreases to $0.51 \mathrm{~cm}^{3} \cdot \mathrm{K} \cdot \mathrm{mol}^{-1}$ at $2 \mathrm{~K}$ (Figure 9a). The shape of the $\chi T$ dependence on temperature for the sample of triradical NN-Vrd-NN is similar to that of the diradical, except that it starts from a high-temperature value of $1.18 \mathrm{~cm}^{3} \cdot \mathrm{K} \cdot \mathrm{mol}^{-1}$, then reaches a maximum value of $1.31 \mathrm{~cm}^{3} \cdot \mathrm{K} \cdot \mathrm{mol}^{-1}$ at $50 \mathrm{~K}$, and drops to $0.64 \mathrm{~cm}^{3} \cdot \mathrm{K} \cdot \mathrm{mol}^{-1}$ at $2 \mathrm{~K}$. Therefore, at high temperatures, $\chi T$ is close to the theoretical value of $1.125 \mathrm{emu} \cdot \mathrm{K} \cdot \mathrm{mol}^{-1}$ for three noninteracting spins $\mathrm{S}=1 / 2$. The maximum value of $\chi T, 1.31 \mathrm{~cm}^{3} \cdot \mathrm{K} \cdot \mathrm{mol}^{-1}$, is much lower than the theoretical value of $1.875 \mathrm{~cm}^{3} \cdot \mathrm{K} \cdot \mathrm{mol}^{-1}$ for $\mathrm{S}=\frac{3}{2}$; this finding is obviously due to the intermolecular antiferromagnetic interactions. To shed light on the origin of the observed magnetic behavior of the I-Vrd-NN diradical and NN-Vrd-NN triradical, intra- and intermolecular exchange interactions were analyzed theoretically using XRD crystal structures. 

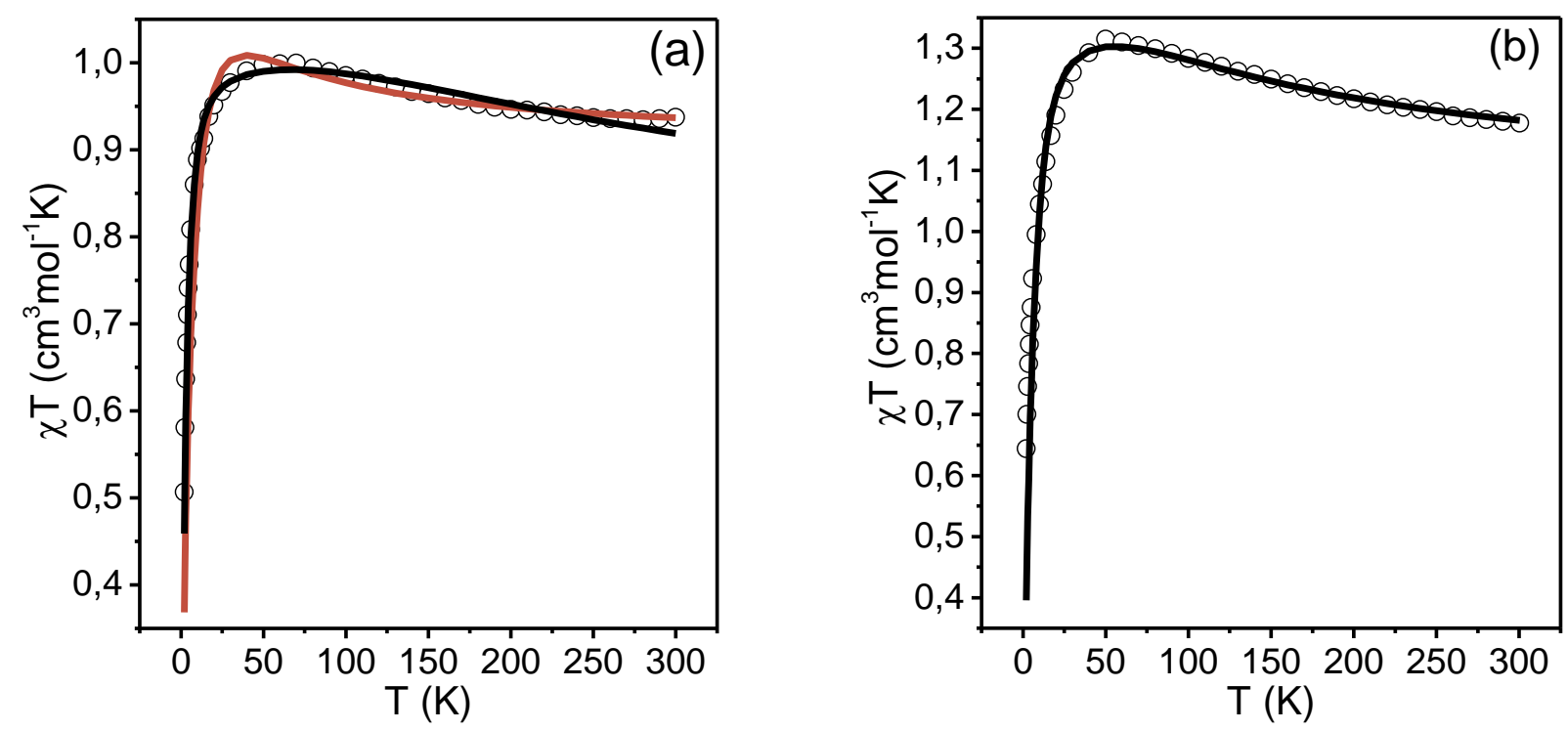

Figure 9. SQUID magnetometry of the polycrystalline samples of the I-Vrd-NN diradical $(a)$ and the NN-Vrd-NN triradical (b): plots of $\chi T$ vs $T$ at $\mathrm{H}=5000$ Oe in warming mode (open circles) and their best-fitting (solid curves) using magnetic models and parameters described in the text.

To compute the parameters of intramolecular exchange interactions in I-Vrd-NN and NN-VrdNN, both high-level CASSCF/CASPT2 and BS-UB3LYP calculations were performed. For the IVrd-NN diradical, CASSCF $(9,10)(10$ electrons in nine MOs, Figure S6.1) calculations predicted a moderate ferromagnetic interaction with singlet-triplet splitting $\Delta E_{\mathrm{ST}} / k_{\mathrm{B}}=69.9 \mathrm{~K}\left(J / k_{\mathrm{B}}=35.0 \mathrm{~K}\right)$. The consideration of the dynamic electron correlation at the CASPT2 level led to a twofold increase in $\Delta E_{\mathrm{ST}} / k_{\mathrm{B}}$ to $134.6 \mathrm{~K}\left(J / k_{\mathrm{B}}=67.3 \mathrm{~K}\right)$. BS-DFT computations for the I-Vrd-NN diradical predicted the same sign of $J$, but a significantly higher absolute value of $J / k_{\mathrm{B}}=283 \mathrm{~K}$. The value of $\Delta E_{\mathrm{ST}} / k_{\mathrm{B}}=$ $2 J / k_{\mathrm{B}}=566 \mathrm{~K}$ predicted at this level is much higher than ambient temperature $(\sim 300 \mathrm{~K})$. It should be noted that such phenomenon is similar to previous calculations for a series of Vrd-NN diradicals: ${ }^{26}$ both procedures predict the same sign, but BS-DFT provides much higher absolute values of $J$.

For the NN-Vrd-NN triradical, CASSCF(9,9)/CASPT2 (nine electrons in nine MOs) calculations predicted an energy splitting between the quartet ground state and two excited doublet states (Figure 10a). To determine the parameters of the exchange interactions between three radical moieties, the following assumptions should be made. If we assume a symmetrical geometry with two equivalent Vrd...NN interactions (Figure 10b), then we obtain the following parameters: $J_{\mathrm{a}} / k_{\mathrm{B}}$ $=28.2 \mathrm{~K}$ and $J_{\mathrm{b}} / k_{\mathrm{B}}=-7.3 \mathrm{~K}$. If we ignore the interaction between the $\mathrm{NN}$ radical centers, then the remaining $J_{\mathrm{a}} / k_{\mathrm{B}}$ and $J_{\mathrm{b}} / k_{\mathrm{B}}$ values (Figure $10 \mathrm{c}$ ) are estimated to be 38.8 and $10.1 \mathrm{~K}$. 
a

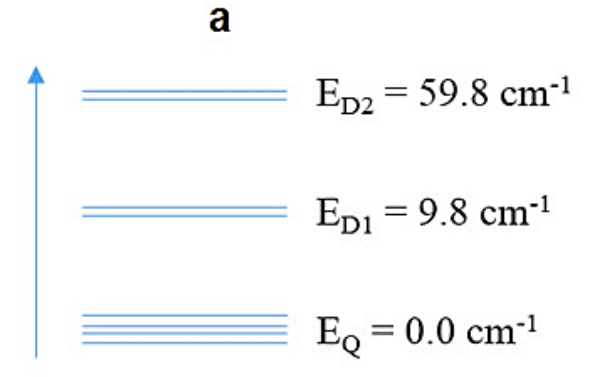

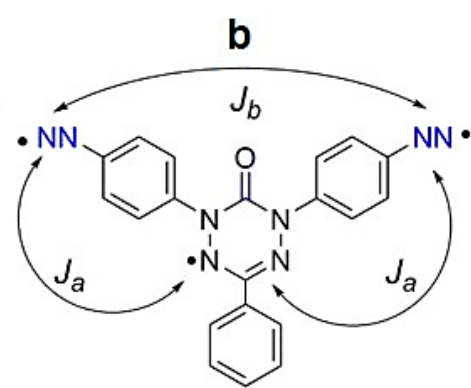

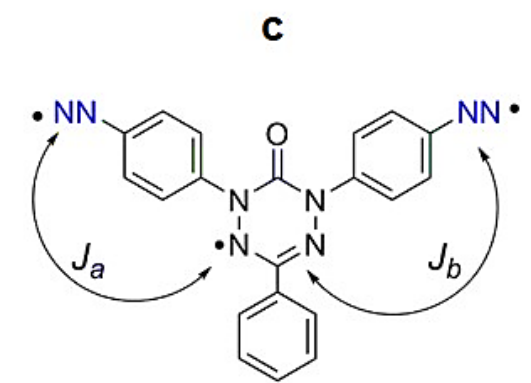

Figure 10. An energy diagram of the lowest-energy states of the NN-Vrd-NN triradical, as computed at the CASSCF(9,9)/CASPT2/def2-TZVP level of theory $(a)$; chemical structure of NNVrd-NN and proposed variants of exchange interactions between radical moieties described by two parameters $(b$ and $c)$.

To select a more adequate interaction scheme (b or c, Figure 10), we also performed calculations of three $J$ parameters by the BS-DFT method. The parameter of the exchange interaction between $\mathrm{NN}$ radical centers turned out to be negligibly small $\left(J / k_{\mathrm{B}}=-0.3 \mathrm{~K}\right)$, whereas $J_{\mathrm{a}} / k_{\mathrm{B}}$ and $J_{\mathrm{b}} / k_{\mathrm{B}}$ were predicted to be 257 and $79 \mathrm{~K}$, respectively. The differences between the calculated $J_{\mathrm{a}}$ and $J_{\mathrm{b}}$ are related to different geometries of $\pi$-conjugated paths in the triradical: although the Vrd and NN groups are practically coplanar (within $\sim 5^{\circ}$ ), the planes of phenylene linkers form different angles relative to this common plane $\left(\sim 29^{\circ}\right.$ and $\left.\sim 52^{\circ}\right)$. Consequently, the model shown in Figure 10c adequately describes the important exchange interactions in the triradical and the values of $J_{\mathrm{a}} / k_{\mathrm{B}}=28.2 \mathrm{~K}$ and $J_{\mathrm{b}} / k_{\mathrm{B}}=-7.3 \mathrm{~K}$ are the best theoretical estimates of their parameters. Furthermore, BS-DFT calculations predict much higher (by approximately an order of magnitude) absolute values of $J$ in comparison to more accurate CASSCF/CASPT2.

To assess intermolecular magnetic interactions, we firstly investigated intermolecular contacts with the participation of atoms having a relatively large spin density. For the di- and triradical, short contacts of the $\mathrm{N}-\mathrm{O} \cdots \mathrm{H}_{\mathrm{Me}}$ type and $\mathrm{N}-\mathrm{O} \ldots \mathrm{H}_{\mathrm{Ph}}$ type were identified at distances of 2.448 to $2.656 \AA$. In addition, NN-Vrd-NN crystals have short $\mathrm{C}=\mathrm{O} \cdots \mathrm{H}_{\mathrm{Me}}$ contacts of 2.487 to $2.700 \AA$. The magnetic interactions resulting from these contacts were calculated at the BS-B3LYP/def2-TZVP level via the conventional model of the nearest diradicals, in which $\mathrm{H}$ atoms are attached to remote radical centers. Parameters $J$ of the intermolecular exchange interactions exceeding $2 \mathrm{~K}$ were predicted only for intradimer contacts in I-Vrd-NN, namely, for the Vrd...NN contact, $J$ is $-16.3 \mathrm{~K}$, and for the Vrd...Vrd interaction, $J$ is $+20.4 \mathrm{~K}$ (for details see SI Section S6).

Therefore, a reasonable magnetic motif of I-Vrd-NN crystals consists of isolated pairs of diradicals, the interactions between which can be accounted in the mean-field approximation (Figure 11, left). This magnetic model is quite simple, it contains four paramagnetic centers and four parameters $\left(\mathrm{J}_{\mathrm{dir}}, \mathrm{J}_{1}, \mathrm{~J}_{2}\right.$, and $\left.\mathrm{zJ}^{\prime}\right)$, but the situation is complicated by the fact that the parameters $\mathrm{J}_{1}$ and $\mathrm{J}_{\text {dir }}$ enter the model symmetrically, although the calculations predict that their values differ in 
magnitude and by sign. Due to this symmetry, the fitting process, even starting from opposite signs of their guess values, tends to converge on the same values: $J_{\mathrm{dir}} / k_{\mathrm{B}}=J_{1} / k_{\mathrm{B}}=139 \mathrm{~K}, J_{2} / k_{\mathrm{B}}=-134 \mathrm{~K}$, $\mathrm{z} J^{\prime} / k_{\mathrm{B}}=-2.3 \mathrm{~K}$, and $\mathrm{g}=2.004$ (Figure 9a, black curve). The simplified model of isolated triradicals in the mean field approximation describes the experiment worse (Figure 9a, red curve) and gives the following best fir parameter values: $J_{\mathrm{dir}} / k_{\mathrm{B}}=26.7 \pm 1.7 \mathrm{~K}, \mathrm{zJ} / k_{\mathrm{B}}=-3.4 \pm 0.1 \mathrm{~K}$, and $\mathrm{g}=2.202 \pm$ 0.005 . Note that the most accurate calculations predict $J_{\mathrm{dir}} / k_{\mathrm{B}}$ to be $67.3 \mathrm{~K}$, which is exactly between the two values extracted from the two types of simulation of experimental dependences.
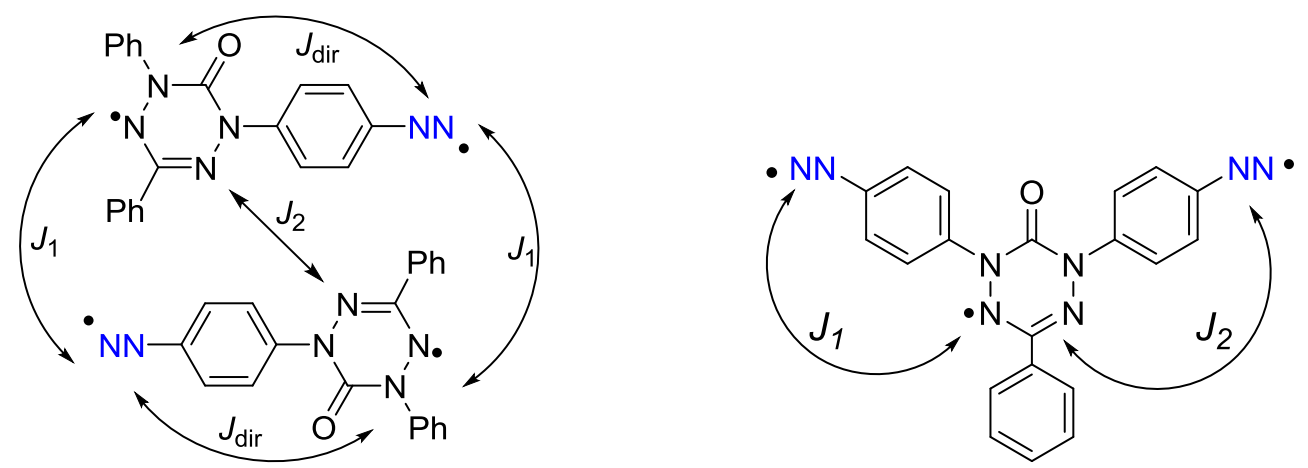

Figure 11. Magnetic motifs of I-Vrd-NN (left) and NN-Vrd-NN (right).

As for the NN-Vrd-NN triradical, the magnetic motif represents isolated paramagnetic species (a triradical with two ferromagnetic interactions), the intermolecular interaction can be described in the mean field approximation (Figure 11, right). The best agreement with experiment was achieved with the following parameters: $J_{1} / k_{\mathrm{B}}=105 \pm 16 \mathrm{~K}, J_{2} / k_{\mathrm{B}}=17 \pm 2 \mathrm{~K}, \mathrm{zJ} / k_{\mathrm{B}}=-5.6 \pm 0.2 \mathrm{~K}$, and $\mathrm{g}=$ $1.954 \pm 0.015$ (Figure 9b). It is worth mentioning that the most accurate theoretical predictions are $J_{1} / k_{\mathrm{B}}=38.8 \mathrm{~K}$ and $J_{2} / k_{\mathrm{B}}=10.1$, which are comparable with the experimental estimates.

\section{CONCLUSION}

In this work, we succeeded in preparing a heterospin triradical containing oxoverdazyl and two NN moieties. The triradical has bridging units of the ethylene-1,1-diyl type and, therefore, a quartet ground state. The triradical is stable in air and possesses good thermal stability in an inert atmosphere. The Vrd and NN centers showed reversible (at $-0.88,0.41 \mathrm{~V}$ vs. $\mathrm{Fc} / \mathrm{Fc}^{+}$) and quasireversible (at -1.48 and $\sim 0.61 \mathrm{~V}$ vs. $\mathrm{Fc} / \mathrm{Fc}^{+}$, in $\mathrm{CH}_{2} \mathrm{Cl}_{2}$ ) redox waves. The magnetic properties were characterized by SQUID magnetometry of polycrystalline powders and by EPR spectroscopy in various matrices and analyzed with reference to XRD data and high-level quantum chemical calculations. The results point to rather strong intramolecular ferromagnetic exchange interactions. The obtained heterospin triradical with quartet ground state can be further functionalized that opens 
possibility for design and synthesis of stable polyradicals with very high spin ground state for the development of purely organic magnetic and electronic materials.

\section{EXPERIMENTAL SECTION}

General Procedures. DMF was dried and distilled over calcium hydride. Other solvents were of reagent quality. All organic reagents and solvents were purchased from commercial suppliers (Sigma-Aldrich, Alfa Aesar, and others) and were used as received. Nitronyl nitroxide-2-ide gold(I) complex $\left(\mathrm{Ph}_{3} \mathrm{P}-\mathrm{Au}-\mathrm{NN}\right)$ was prepared according to a previously reported procedure. ${ }^{39}$ All reactions were carried out under argon in oven-dried Schlenk flasks. Routine monitoring of the reactions was performed by means of silica-coated aluminum plates (Merck, Silica gel 60, F254), which were analyzed under UV light at $254 \mathrm{~nm}$. Chromatography was carried out on silica (0.050-0.160 mm) for column chromatography.

IR spectra were recorded with a Bruker Tensor 27 FTIR spectrometer in KBr pellets. UV-Vis spectra were acquired in a $\mathrm{CH}_{2} \mathrm{Cl}_{2}$ solution on a Bruker Vector-22 spectrometer. Melting points were determined by means of an FP 900 Thermosystem microscope melting point apparatus (Mettler-Toledo International Inc., Zürich, Switzerland), and elemental analysis was performed on a Carlo Erba CHN analyzer.

Cyclic voltammetry measurements were performed at a sweep rate of $0.1 \mathrm{~V} \cdot \mathrm{s}^{-1}$ in a deoxygenated $\mathrm{CH}_{2} \mathrm{Cl}_{2}$ solution by a computer-controlled P-8 nano potentiostat/galvanostat (Elins, Russia) in combination with a three-electrode cell (Gamry), with $0.1 \mathrm{M} \mathrm{Bu}_{4} \mathrm{NPF}_{6}$ as a supporting electrolyte. Pt, a Pt wire, and $\mathrm{Ag} / \mathrm{AgCl}$ served as a working, counter, and reference electrode, respectively. The reference electrode was calibrated by measurement of the redox potentials of ferrocene. The redox event centered at $0 \mathrm{mV}$ corresponds to the ferrocene/ferrocenium redox couple (ferrocene added as an internal reference).

All EPR data were collected using X/Q-band pulse/cw EPR spectrometer Bruker Elexsys E580 equipped with an Oxford Instruments temperature control system ( $\mathrm{T}=4$ to $300 \mathrm{~K}$ ). For all spectral simulations, the EasySpin toolbox for Matlab was utilized. ${ }^{47}$

The magnetic susceptibility of the polycrystalline samples was measured with a Quantum Design MPMSXL SQUID magnetometer in the temperature range 2-300 K with magnetic field of up to $5 \mathrm{kOe}$. None of complexes exhibited any field dependence of molar magnetic susceptibility at low temperatures. Diamagnetic corrections were made using the Pascal constants. The spin Hamiltonian in general form of $H=-2 \Sigma J_{i j} S_{i} S_{j}$ was used for an analysis of the experimental $\chi T(\mathrm{~T})$ dependencies. 


\section{Synthesis of diiodoverdazyl radical I-Vrd-I, diradical I-Vrd-NN, and triradical NN-Vrd-}

NN. Standard techniques for synthesis in an argon atmosphere were used, including Schlenk glassware and manifold high-vacuum lines. The multistep, efficient synthesis and characterization of starting diiodoverdazyl building block I-Vrd-I are outlined in Supporting Information (Scheme S1).

Synthesis of diradical I-Vrd-NN and triradical $\mathbf{N N}$-Vrd-NN. Verdazyl iodide I-Vrd-I, $\mathrm{Ph}_{3} \mathrm{P}-$ $\mathrm{Au}-\mathrm{NN}$, and $\mathrm{Pd}\left(\mathrm{PPh}_{3}\right)_{4}$ were dissolved in DMF under argon (amounts of the reagents are given in Table 3). The mixture was heated at $70{ }^{\circ} \mathrm{C}$ until full conversion of the starting Au-complex (monitored by TLC in dichloromethane-EtOAc at 35:1). Then, the reaction mixture was cooled to room temperature, and the solvent was removed in vacuo. Products I-Vrd-NN and NN-Vrd-NN were isolated by column chromatography $\left(\mathrm{SiO}_{2}\right.$, from EtOAc-hexane at 1:3 to EtOAc-hexane at 1:1 to EtOAc alone) and next crystallized from an acetone-heptane solution.

Table 3. Yields of I-Vrd-NN and NN-Vrd-NN depending on the reagent ratio and reaction time.

\begin{tabular}{ccccccc}
\hline \multirow{2}{*}{ Entry } & \multirow{2}{*}{$\mathbf{I - V r d - I , ~ m m o l}$} & $\mathrm{Ph}_{3} \mathrm{P}-\mathrm{Au}-\mathrm{NN}, \mathrm{mmol}$ & $\mathrm{Pd}\left(\mathrm{PPh}_{3}\right)_{4}, \%$ mol. & \multirow{2}{*}{ Time, $\mathrm{h}$} & \multicolumn{3}{c}{ Yields, \% } \\
& & & & & I-Vrd-NN & NN-Vrd-NN \\
\hline 1 & 0.135 & 0.202 & 10 & 1.5 & 34 & 27 \\
2 & 0.4211 & 0.6318 & 10 & 1.5 & 20 & 3 \\
3 & 0.0863 & 0.259 & 20 & 3 & 27 & 14 \\
\hline
\end{tabular}

1-(4-(4,4,5,5-Tetramethyl-3-oxide-1-oxyl-4,5-dihydro-1H-imidazol-2-yl)phenyl)-3-(4-iodophenyl)5-phenyl-2-oxoverdazyl diradical (I-Vrd-NN). Dark purple powder. M.p. $\left(5^{\circ} \mathrm{C} / \mathrm{min}\right): 129.7{ }^{\circ} \mathrm{C}$<smiles>CN1C(c2ccccc2)=NN(c2ccc(C3=[N+]([O-])C(C)(C)C(C)(C)N3C)cc2)C(=O)N1c1ccc(I)cc1</smiles>
(decomp.). UV $\left(\mathrm{CH}_{2} \mathrm{Cl}_{2}\right) \lambda_{\max }(\lg \varepsilon): 574$ (3.49), 368 (4.36), 350 (4.25), 242 (4.50) nm. IR (KBr, cm $\left.{ }^{-1}\right): 3439,3398,3090,3064$, 3036, 2987, 2949, 2926, 2868, 2854, 1761, 1703, 1599, 1581, 1522, $1481,1450,1414,1390,1365,1311,1279,1248,1217,1167,1124$, $1101,1061,1041,1022,1005,970,895,868,837,825,806,773$, 712, 694, 656, 634, 619, 542, 527, 509, 451. High-resolution mass spectrometry (HRMS; ESI-QTOF) calcd. for $\mathrm{C}_{27} \mathrm{H}_{25} \mathrm{IN}_{6} \mathrm{O}_{3}\left[\mathrm{M}^{-}\right]$: 608.1033. Found: 608.1039. Anal. calcd. for $\mathrm{C}_{27} \mathrm{H}_{25} \mathrm{IN}_{6} \mathrm{O}_{3}$-acetone: C, 54.06; H, 4.69; N, 12.61. Found: C, 54.11; H, 4.64; N, 12.57 . 1,3-(4-(4,4,5,5-Tetramethyl-3-oxide-1-oxyl-4,5-dihydro-1H-imidazol-2-yl)phenyl)-5-phenyl-2-

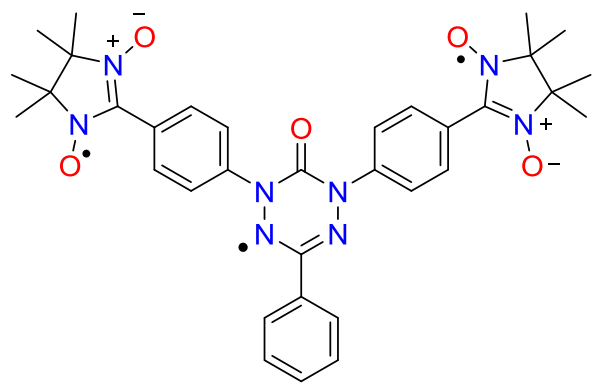

oxoverdazyl triradical (NN-Vrd-NN): Dark purple powder. M.p. $\left(1^{\circ} \mathrm{C} / \mathrm{min}\right): 133.6^{\circ} \mathrm{C}$ (decomp.). UV $\left(\mathrm{CH}_{2} \mathrm{Cl}_{2}\right) \lambda_{\max },(\lg$ ع): 583 (3.56), 369 (4.55), 263 (4.48) nm. FT-IR (KBr, cm$\left.{ }^{-1}\right)$ : 3437, 3091, 3057, 2987, 2937, 2872, 1705, 1599, 1520, 1483, $1468,1450,1435,1421,1412,1389,1365,1311,1248,1217$, 
1190, 1167, 1134, 1101, 1074, 1043, 1018, 968, 868, 839, 773, 760, 721, 694, 656, 634, 619, 542, 527, 446. HRMS (ESI-QTOF) calcd. for $\mathrm{C}_{34} \mathrm{H}_{37} \mathrm{~N}_{8} \mathrm{O}_{5}\left[\mathrm{M}^{-}\right]$: 637.2887. Found: 637.2878. Anal. calcd. for $\mathrm{C}_{34} \mathrm{H}_{37} \mathrm{~N}_{8} \mathrm{O}_{5} \bullet$ acetone: C, 63.87; H, 6.23; N, 16.10. Found: C, 63.71; H, 6.25; N, 16.13 .

X-ray Crystallography. Crystals of I-Vrd-NN and NN-Vrd-NN for this analysis were prepared by slow evaporation from a solution in acetone-heptane at $5{ }^{\circ} \mathrm{C}$. Data collection was performed on a Bruker Kappa Apex II CCD diffractometer using $\varphi, \omega$-scans of narrow $\left(0.5^{\circ}\right)$ frames with Mo K $\alpha$ radiation $(\lambda=0.71073 \AA)$ and a graphite monochromator. The structures were solved by direct methods in the SHELX-97 software $^{48}$ and were refined by the full-matrix least-squares method over all F2 in anisotropic approximation using the SHELXL-2014/7 software. ${ }^{49}$ Absorption corrections were made by an empirical multiscan method with the SADABS program. ${ }^{50}$ Hydrogen atoms' positions were calculated with the riding model. The crystallographic data are listed in Table 4.

The obtained crystal structures were analyzed for short contacts between nonbonded atoms using PLATON ${ }^{51,52}$ and MERCURY programs. ${ }^{53}$ The crystal structure of I-Vrd-NN is formed by one solvating molecule of acetone per unit. The free volume accessible to the solvent in the NNVrd-NN crystal derived from the PLATON ${ }^{51}$ routine analysis is $19 \%\left(1504 \AA^{3}\right)$. This volume is occupied by highly disordered solvent molecules, which could not be modeled as a set of discrete atomic sites. We employed the PLATON/SQUEEZE procedure to calculate the diffraction contribution from the solvent region and thereby produced a set of solvent-free diffraction intensities. The most probable solvate molecule for NN-Vrd-NN is acetone.

CCDC 2068922, 2068923 contain the supplementary crystallographic data for this paper. These data can be obtained free of charge via http://www.ccdc.cam.ac.uk/cgi-bin/catreq.cgi, or from the Cambridge Crystallographic Data Centre, 12 Union Road, Cambridge CB2 1EZ, UK; fax: (+44) 1223336 033; or e-mail: deposit@ccdc.cam.ac.uk.

Table 4. XRD data for compounds I-Vrd-NN and NN-Vrd-NN.

\begin{tabular}{lll}
\hline Compound & I-Vrd-NN & NN-Vrd-NN \\
\hline Empirical formula & $\mathrm{C}_{27} \mathrm{H}_{25} \mathrm{~N}_{6} \mathrm{O}_{3} \mathrm{I} \cdot \mathrm{C}_{3} \mathrm{H}_{6} \mathrm{O}$ & $\mathrm{C}_{34} \mathrm{H}_{37} \mathrm{~N}_{8} \mathrm{O}_{5} \cdot$ Solvent \\
Formula weight & 666.51 & 637.71 \\
Temperature, K & $200(2)$ & $200(2)$ \\
Wavelength, $\AA$ & 0.71073 & 0.71073 \\
Crystal system & Triclinic & Tetragonal \\
Space group & $\mathrm{P}-1$ & $\mathrm{P} 44_{2} / \mathrm{n}$ \\
Unit cell dimensions $a, \AA$ & $10.8641(6)$ & $35.3952(18)$ \\
$b, \AA$ & $11.4045(5)$ & $35.3952(18)$ \\
$c, \AA$ & $12.9351(7)$ & $6.2920(4)$ \\
$\alpha,{ }^{\circ}$ & $85.947(2)$ & 90
\end{tabular}




\begin{tabular}{lll}
$\beta,{ }^{\circ}$ & $85.585(2)$ & 90 \\
$\gamma^{\circ}{ }^{\circ}$ & $66.789(2)$ & 90 \\
Volume, $\AA^{3}$ & $1467.1(1)$ & $7882.7(9)$ \\
$\mathrm{Z}$ & 2 & 8 \\
Density (calcd.), $\mathrm{Mg} \cdot \mathrm{m}^{-3}$ & 1.509 & 1.075 \\
Abs. coefficient, $\mathrm{mm}^{-1}$ & 1.137 & 0.074 \\
$\mathrm{~F}(000)$ & 676 & 2696 \\
Crystal size, $\mathrm{mm}^{3}$ & $0.04 \times 0.20 \mathrm{x} 0.90$ & $0.04 \times 0.08 \times 0.90$ \\
$\Theta$ range for data collection, ${ }^{\circ}$ & $2.04-30.07$ & $1.15-26.12$ \\
Index ranges & $-15 \leq \mathrm{h} \leq 15$, & $-43 \leq \mathrm{h} \leq 43$, \\
& $-16 \leq \mathrm{k} \leq 13$, & $-43 \leq \mathrm{k} \leq 43$, \\
& $-18 \leq 1 \leq 16$ & $-7 \leq 1 \leq 7$ \\
Reflections collected & 31551 & 91377 \\
Independent reflections & $7843 \mathrm{R}(\mathrm{int})=0.034$ & $7820 \mathrm{R}(\mathrm{int})=0.125$ \\
Completeness to $\theta, \%$ & 99.9 & 99.9 \\
Data / restraints / parameters & $7843 / 0 / 376$ & $7820 / 0 / 432$ \\
Goodness-of-fit on $F^{2}$ & 1.005 & 1.03 \\
Final R indices $I>2 \sigma(I)$ & $\mathrm{R}_{1}=0.0375, \mathrm{wR}_{2}=0.0951$ & $\mathrm{R}_{1}=0.0619, \mathrm{wR}_{2}=0.1298$ \\
Final R indices (all data) & $\mathrm{R}_{1}=0.0606, \mathrm{wR}_{2}=0.1096$ & $\mathrm{R}_{1}=0.1345, \mathrm{wR}_{2}=0.1561$ \\
Largest diff. peak / hole, $\mathrm{e} \cdot \AA^{-3}$ & $1.01 /-0.56$ & $0.26 /-0.21$ \\
CCDC & 2068922 & 2068923 \\
\hline
\end{tabular}

Computational Details. For the I-Vrd-I radical, all calculations were performed for the geometry optimized at the UB3LYP/def2-TZVP level. ${ }^{54,55,56}$ For the I-Vrd-NN diradical and NNVrd-NN triradical, the calculations were mainly performed for XRD structures. Electronic absorption spectra (UV-Vis spectra) of the paramagnetic compounds were computed via timedependent DFT calculations ${ }^{57}$ with the B3LYP functional ${ }^{54,55}$ and the def2-TZVP basis set. ${ }^{56}$ In the case of the I-Vrd-NN diradical and NN-Vrd-NN triradical, the UV-Vis spectra were calculated for their high-spin ground states (a triplet state for I-Vrd-NN and a quartet state for NN-Vrd-NN, see Section S3 providing justification for the ground state nature).

The g- and ZFS tensors were also computed at UB3LYP and ROPBE ${ }^{58,59}$ levels, respectively, with the def2-TZVP basis set. The parameters of the intramolecular exchange interactions $(J)$ were computed for pairs of paramagnetic centers $\left(H=-2 J \hat{\vec{S}}_{1} \hat{\vec{S}}_{2}\right)$ by two procedures. The accurate $a b$ initio $\mathrm{CASSCF}^{60}$ and CASSCF/NEVPT2. ${ }^{61,62}$ procedures were mainly employed. The spinunrestricted broken-symmetry (BS) approach $^{63}$ was utilized too. The energies of the high-spin states $\left(E^{H S}\right)$ and low-spin states within the BS approach $\left(E_{B S}^{L S}\right)$ were calculated at the UB3LYP level of theory, and the $J$ values were computed according to the following formula: ${ }^{64}$

$$
J=\frac{E^{H S}-E_{B S}^{L S}}{\left\langle S^{2}\right\rangle^{H S}-\left\langle S^{2}\right\rangle_{B S}^{L S}}
$$

Parameters of the intermolecular exchange interactions $(J)$ were calculated only at the BSUB3LYP/def2-TZVP level. These values were calculated only for pairs of model radicals. To 
obtain model radicals, hydrogen atoms were added to remote radical centers of the di- and triradical. All the calculations were performed using the ORCA 4.0.1 software suite. ${ }^{65}$

\section{ACKNOWLEDGMENTS}

This research was supported by the Russian Science Foundation (project No. 20-73-00236). The authors would like to acknowledge the Multi-Access Chemical Research Center SB RAS for spectral and analytical measurements. The authors thank Dr. Alexander Maryasov (Novosibirsk Institute of Organic Chemistry) for a fruitful discussion and useful comments. The authors would like to acknowledge the Research Resource Center "Irkutsk Supercomputer Center SB RAS" for the computational resources.

\section{REFERENCES}

(1) $\pi$-Electron Magnetism; Veciana, J., Arčon, D., Deumal, M., Inoue, K., Kinoshita, M., Novoa, J. J., Palacio, F., Prassides, K., Rawson, J. M., Rovira, C., Eds.; Structure and Bonding; Springer Berlin Heidelberg: Berlin, Heidelberg, 2001; Vol. 100. https://doi.org/10.1007/3-540-44684-2.

(2) Gatteschi, D.; Sessoli, R.; Villain, J. Molecular Nanomagnets; Oxford University Press, 2006; Vol. 15. https://doi.org/10.1093/acprof:oso/9780198567530.001.0001.

(3) Abe, M. Diradicals. Chem. Rev. 2013, 113 (9), 7011-7088. https://doi.org/10.1021/cr400056a.

(4) Nishinaga, T. Organic Redox Systems: Synthesis, Properties, and Applications; Nishinaga, T., Ed.; John Wiley \& Sons, Inc: Hoboken, NJ, 2015, pp. 269 - 285. https://doi.org/10.1002/9781118858981.

(5) Baumgarten, M. High Spin Organic Molecules. Mater. Energy 2018, 4, 1-93. https://doi.org/10.1142/9789813230200_0001.

(6) Sanvito, S. Molecular Spintronics. Chem. Soc. Rev. 2011, 40 (6), 3336-3355. https://doi.org/10.1039/c1cs15047b.

(7) Hu, G.; Xie, S.; Wang, C.; Timm, C. Spin-Dependent Transport and Functional Design in Organic Ferromagnetic Devices. Beilstein J. Nanotechnol. 2017, 8 (1), 1919-1931. https://doi.org/10.3762/bjnano.8.192.

(8) Gaudenzi, R.; Burzurí, E.; Reta, D.; Moreira, I. D. P. R.; Bromley, S. T.; Rovira, C.; Veciana, J.; Van Der Zant, H. S. J. Exchange Coupling Inversion in a High-Spin Organic Triradical Molecule. Nano Lett. 2016, 16 (3), 2066-2071. https://doi.org/10.1021/acs.nanolett.6b00102. 
(9) Akasaka, T.; Osuka, A.; Fukuzumi, S.; Kandori, H.; Aso, Y. Chemical Science of $\pi$-Electron Systems; Akasaka, T., Osuka, A., Fukuzumi, S., Kandori, H., Aso, Y., Eds.; Springer Japan: Tokyo, 2015; Vol. 8. https://doi.org/10.1007/978-4-431-55357-1.

(10) Sugisaki, K.; Nakazawa, S.; Toyota, K.; Sato, K.; Shiomi, D.; Takui, T. Quantum Chemistry on Quantum Computers: A Method for Preparation of Multiconfigurational Wave Functions on Quantum Computers without Performing Post-Hartree-Fock Calculations. ACS Cent. Sci. 2019, 5 (1), 167-175. https://doi.org/10.1021/acscentsci.8b00788.

(11) Longuet-Higgins, H. C. Some Studies in Molecular Orbital Theory. I. Resonance Structures and Molecular Orbitals in Unsaturated Hydrocarbons. J. Chem. Phys. 1950, 18 (3), 265-274. https://doi.org/10.1063/1.1747618.

(12) Borden, W. T.; Davidson, E. R. Effects of Electron Repulsion in Conjugated Hydrocarbon Diradicals. J. Am. Chem. Soc. 1977, 99 (14), 4587-4594. https://doi.org/10.1021/ja00456a010.

(13) Rajca, A.; Utamapanya, S. Poly(Arylmethyl) Quartet Triradicals and Quintet Tetraradicals. J. Am. Chem. Soc. 1993, 115 (6), 2396-2401. https://doi.org/10.1021/ja00059a039.

(14) Rajca, A.; Wongsriratanakul, J.; Rajca, S. Organic Spin Clusters: Ferromagnetin Spin Coupling through a Biphenyl Unit in Polyarylmethyl Tri-, Penta-, Hepta-, and Hexadecaradicals. J. Am. Chem. Soc. 1997, 119 (48), 11674-11686. https://doi.org/10.1021/ja972378b.

(15) Gallagher, N. M.; Olankitwanit, A.; Rajca, A. High-Spin Organic Molecules. J. Org. Chem. 2015, 80 (3), 1291-1298. https://doi.org/10.1021/jo502505r.

(16) Ovchinnikov, A. A. Multiplicity of the Ground State of Large Alternant Organic Molecules with Conjugated Bonds - (Do Organic Ferromagnetics Exist?). Theor. Chim. Acta 1978, 47 (4), 297-304. https://doi.org/10.1007/BF00549259.

(17) Klein, D. J.; Nelin, C. J.; Alexander, S.; Matsen, F. A. High-Spin Hydrocarbons. J. Chem. Phys. 1982, 77 (6), 3101-3108. https://doi.org/10.1063/1.444233.

(18) Inoue, K.; Iwamura, H. 2- [p(N- tert- butyl- N- oxyamino)Phenyl]- 4,4,5,5- tetramethyl4,5- dihydroimidazol- 3- oxide- 1- oxyl, a Stable Diradical with a Triplet Ground State. Angew. Chemie Int. Ed. English 1995, 34 (8), 927-928. https://doi.org/10.1002/anie.199509271.

(19) Tanaka, M.; Matsuda, K.; Itoh, T.; Iwamura, H. Syntheses and Magnetic Properties of Stable Organic Triradicals with Quartet Ground States Consisting of Different Nitroxide Radicals. $J$. Am. Chem. Soc. 1998, 120 (29), 7168-7173. https://doi.org/10.1021/ja980817g.

(20) Suzuki, S.; Furui, T.; Kuratsu, M.; Kozaki, M.; Shiomi, D.; Sato, K.; Takui, T.; Okada, K. Nitroxide-Substituted Nitronyl Nitroxide and Iminonitroxide. J. Am. Chem. Soc. 2010, 132 (45), 15908-15910. https://doi.org/10.1021/ja107769z. 
(21) Tretyakov, E. V.; Tolstikov, S. E.; Romanenko, G. V.; Bogomyakov, A. S.; Stass, D. V.; Maryasov, A. G.; Gritsan, N. P.; Ovcharenko, V. I. Method for the Synthesis of a Stable Heteroatom Analog of Trimethylenemethane. Russ. Chem. Bull. 2011, 60 (12), 2608-2612. https://doi.org/10.1007/s11172-011-0400-8.

(22) Rajca, A.; Olankitwanit, A.; Rajca, S. Triplet Ground State Derivative of Aza- m -Xylylene Diradical with Large Singlet-Triplet Energy Gap. J. Am. Chem. Soc. 2011, 133 (13), 4750-4753. https://doi.org/10.1021/ja200708b.

(23) Gallagher, N. M.; Bauer, J. J.; Pink, M.; Rajca, S.; Rajca, A. High-Spin Organic Diradical with Robust Stability. J. Am. Chem. Soc. 2016, 138 (30), 9377-9380. https://doi.org/10.1021/jacs.6b05080.

(24) Wang, W.; Chen, C.; Shu, C.; Rajca, S.; Wang, X.; Rajca, A. S = 1 Tetraazacyclophane Diradical Dication with Robust Stability: A Case of Low-Temperature One-Dimensional Antiferromagnetic Chain. J. Am. Chem. Soc. 2018, 140 (25), 7820-7826. https://doi.org/10.1021/jacs.8b02415.

(25) Gallagher, N.; Zhang, H.; Junghoefer, T.; Giangrisostomi, E.; Ovsyannikov, R.; Pink, M.; Rajca, S.; Casu, M. B.; Rajca, A. Thermally and Magnetically Robust Triplet Ground State Diradical. J. Am. Chem. Soc. 2019, 141, 4764-4774. https://doi.org/10.1021/jacs.9b00558.

(26) Tretyakov, E. V.; Zhivetyeva, S. I.; Petunin, P. V.; Gorbunov, D. E.; Gritsan, N. P.; Bagryanskaya, I. Y.; Bogomyakov, A. S.; Postnikov, P. S.; Kazantsev, M. S.; Trusova, M. E.; Shundrina, I. K.; Zaytseva, E. V.; Parkhomenko, D. A.; Bagryanskaya, E. G.; Ovcharenko, V. I. Ferromagnetically Coupled $S=1$ Chains in Crystals of Verdazyl-Nitronyl Nitroxide Diradicals. Angew. Chemie - Int. Ed. 2020, 59 (46), 20704-20710. https://doi.org/10.1002/anie.202010041.

(27) Veciana, J.; Rovira, C.; Ventosa, N.; Crespo, M. I.; Palacio, F. Stable Polyradicals with HighSpin Ground States. 2. Synthesis and Characterization of a Complete Series of Polyradicals Derived from 2,4,6-Trichloro- $\alpha, \alpha, \alpha^{\prime}, \alpha^{\prime}, \alpha^{\prime \prime}, \alpha^{\prime \prime}$-Hexakis(Pentachlorophenyl)Mesitylene with $\mathrm{S}=$ 1/2, 1, and 3/2 Ground States. J. Am. Chem. Soc. 1993, 115 (1), 57-64. https://doi.org/10.1021/ja00054a008.

(28) Kothe, G.; Neugebauer, F. A.; Zimmermann, H. 1,3,5-Benzenetriyltris(1,5-diphenyl-3verdazyl): A Radical Having a Nearly Degenerate Doublet-Quartet Ground State. Angew. Chem. Int. Ed. 1972, 11, 830-832. https://doi.org/10.1002/anie.197208302

(29) Rey, P.; Ovcharenko, V. I. Copper(II) Nitroxide Molecular Spin-Transition Complexes. Magn. Mol. to Mater. 2003, 4-5 (Ii), 41-63. https://doi.org/10.1002/9783527620548.ch2c.

(30) Iwamura, H.; Inoue, K. Magnetic Ordering in Metal Coordination Complexes with Aminoxyl Radicals; 2003; Vol. 2-5. https://doi.org/10.1002/9783527620548.ch2a. 
(31) Dulog, L.; Kim, J. S. A Stable Triradical Compound and Its Unusual Magnetic Properties. Angew. Chemie Int. Ed. English 1990, 29 (4), 415-417. https://doi.org/10.1002/anie.199004151.

(32) Izuoka, A.; Fukada, M.; Sugawara, T. Stable Mono-, Di-, and Triradicals as Constituent Molecules for Organic Ferrimagnets. Mol. Cryst. Liq. Cryst. Sci. Technol. Sect. A. Mol. Cryst. Liq. Cryst. 1993, 232 (1), 103-108. https://doi.org/10.1080/10587259308035704.

(33) Izuoka, A.; Fukada, M.; Sugawara, T.; Sakai, M.; Bandow, S. Magnetic Property of 1,3,5Tris $\left(4^{\prime}, 4^{\prime}, 5^{\prime}, 5^{\prime}\right.$-Tetramethylimidazolin-2'-Y1)Benzene 3',3",3'"'-Trioxide $1^{\prime}, 1^{\prime \prime}, 1^{\prime \prime \prime}$-Trioxyl in $1: 1$ Mixed Crystals with 1,3,5-Trinitrobenzene. Chem. Lett. 1992, 21 (8), 1627-1630. https://doi.org/10.1246/cl.1992.1627.

(34) Izuoka, A.; Fukada, M.; Kumai, R.; Itakura, M.; Hikami, S.; Sugawara, T. Magnetically Coupled Molecular System Composed of Organic Radicals with Different Spin Multiplicities. J. Am. Chem. Soc. 1994, 116 (6), 2609-2610. https://doi.org/10.1021/ja00085a047.

(35) Kanno, F.; Inoue, K.; Koga, N.; Iwamura, H. Persistent 1,3,5-Benzenetriyltris(N-Tert-Butyl Nitroxide) and Its Analogs with Quartet Ground States. Intramolecular Triangular Exchange Coupling among Three Nitroxide Radical Centers. J. Phys. Chem. 1993, 97 (50), 13267-13272. https://doi.org/10.1021/j100152a034.

(36) Hayami, S.; Inoue, K. Structure and Magnetic Property of the Organic Triradical with Triazine Skeleton; 2,4,6-Tris $\{\mathrm{p}$-(N-Oxy-N-Tert-Butylamino)Phenyl $\}$ triazine. Chemistry Letters. 1999, pp 545-546. https://doi.org/10.1246/cl.1999.545.

(37) Lahti, P. M.; Liao, Y.; Julier, M.; Palacio, F. S-Triazine As an Exchange Linker in Organic High-Spin Molecules. Synth. Met. 2001, 122 (3), 485-493. https://doi.org/10.1016/S03796779(01)00340-X.

(38) Ishida, T.; Iwamura, H. Bis[3-Tert-Butyl-5-(N-Oxy-Tert-Butylamino)Phenyl] Nitroxide in a Quartet Ground State: A Prototype for Persistent High-Spin Poly [(Oxyimino)-1,3-Phenylenes]. J. Am. Chem. Soc. 1991, 113 (11), 4238-4241. https://doi.org/10.1021/ja00011a028.

(39) Tanimoto, R.; Suzuki, S.; Kozaki, M.; Okada, K. Nitronyl Nitroxide as a Coupling Partner: PdMediated Cross-Coupling of (Nitronyl Nitroxide-2-Ido)(Triphenylphosphine)Gold(i) with Aryl Halides. Chem. Lett. 2014, 43 (5), 678-680. https://doi.org/10.1246/cl.131162.

(40) Haraguchi, M.; Tretyakov, E.; Gritsan, N.; Romanenko, G.; Gorbunov, D.; Bogomyakov, A.; Maryunina, K.; Suzuki, S.; Kozaki, M.; Shiomi, D.; Sato, K.; Takui, T.; Nishihara, S.; Inoue, K.; Okada, K. (Azulene-1,3-Diyl)-Bis(Nitronyl Nitroxide) and (Azulene-1,3-Diyl)Bis(Iminonitroxide) and Their Copper Complexes. Chem. - An Asian J. 2017, 12 (22), 29292941. https://doi.org/10.1002/asia.201701085. 
(41) Tretyakov, E. V; Ovcharenko, V. I. The Chemistry of Nitroxide Radicals in the Molecular Design of Magnets. Russ. Chem. Rev. 2009, 78 (11), 971-1012. https://doi.org/10.1070/rc2009v078n11abeh004093.

(42) Votkina, D. E.; Petunin, P. V.; Zhivetyeva, S. I.; Bagryanskaya, I. Y.; Uvarov, M. N.; Kazantsev, M. S.; Trusova, M. E.; Tretyakov, E. V.; Postnikov, P. S. Preparation of Multi-Spin Systems: A Case Study of Tolane-Bridged Verdazyl-Based Hetero-Diradicals. European J. Org. Chem. 2020, 2020 (13), 1996-2004. https://doi.org/10.1002/ejoc.202000044.

(43) Barskaya, I. Y.; Veber, S. L.; Suturina, E. A.; Sherin, P. S.; Maryunina, K. Y.; Artiukhova, N. A.; Tretyakov, E. V.; Sagdeev, R. Z.; Ovcharenko, V. I.; Gritsan, N. P.; Fedin, M. V. Spin-StateCorrelated Optical Properties of Copper(II)-Nitroxide Based Molecular Magnets. Dalt. Trans. 2017, 46 (38), 13108-13117. https://doi.org/10.1039/c7dt02719b.

(44) Petunin, P. V.; Votkina, D. E.; Trusova, M. E.; Rybalova, T. V.; Amosov, E. V.; Uvarov, M. N.; Postnikov, P. S.; Kazantsev, M. S.; Mostovich, E. A. Oxidative Addition of Verdazyl Halogenides to $\mathrm{Pd}\left(\mathrm{PPh}_{3}\right)_{4}$. New J. Chem. 2019, 43 (38), 15293-15301. https://doi.org/10.1039/c9nj03361k.

(45) Massolle, A.; Dresselhaus, T.; Eusterwiemann, S.; Doerenkamp, C.; Eckert, H.; Studer, A.; Neugebauer, J. Towards Reliable References for Electron Paramagnetic Resonance Parameters Based on Quantum Chemistry: The Case of Verdazyl Radicals. Phys. Chem. Chem. Phys. 2018, 20 (11), 7661-7675. https://doi.org/10.1039/c7cp05657e.

(46) Tolstikov, S. E.; Tretyakov, E. V.; Gorbunov, D. E.; Zhurko, I. F.; Fedin, M. V.; Romanenko, G. V.; Bogomyakov, A. S.; Gritsan, N. P.; Mazhukin, D. G. Reaction of Paramagnetic Synthon, Lithiated 4,4,5,5-Tetramethyl-4,5-Dihydro-1H-Imidazol-1-Oxyl 3-Oxide, with Cyclic Aldonitrones of the Imidazole Series. Chem. - A Eur. J. 2016, 22 (41), 14598-14604. https://doi.org/10.1002/chem.201602049.

(47) Cai, S.; Chen, C.; Sun, Z.; Xi, C. CuCl-Catalyzed Ortho Trifluoromethylation of Arenes and Heteroarenes with a Pivalamido Directing Group. Chem. Commun. 2013, 49 (40), 4552-4554. https://doi.org/10.1039/c3cc41331d.

(48) Sheldrick, G. M. SHELX-97, Programs for Crystal Structure Analysis (Release 97-2), University of Göttingen, Germany, 1997.

(49) Sheldrick, G. M. SHELXT - Integrated Space-Group and Crystal-Structure Determination. Acta Crystallogr. Sect. A Found. Crystallogr. 2015, $71 \quad$ (1), 3-8. https://doi.org/10.1107/S2053273314026370.

(50) SADABS, v. 2008-1, Bruker AXS, Madison, WI, USA, 2008. 
(51) Spek, A. L. PLATON, A Multipurpose Crystallographic Tool (Version 10M), Utrecht University, Utrecht, The Netherlands, 2003.

(52) Spek, A. L. Single-Crystal Structure Validation with the Program PLATON. J. Appl. Crystallogr. 2003, 36 (1), 7-13. https://doi.org/10.1107/S0021889802022112.

(53) Macrae, C. F.; Edgington, P. R.; McCabe, P.; Pidcock, E.; Shields, G. P.; Taylor, R.; Towler, M.; Van De Streek, J. Mercury: Visualization and Analysis of Crystal Structures. J. Appl. Crystallogr. 2006, 39 (3), 453-457. https://doi.org/10.1107/S002188980600731X.

(54) Becke, A. D. Density-Functional Thermochemistry. III. The Role of Exact Exchange. J. Chem. Phys. 1993, 98 (7), 5648-5652. https://doi.org/10.1063/1.464913.

(55) Lee, C.; Yang, W.; Parr, R. G. Development of the Colle-Salvetti Correlation-Energy Formula into a Functional of the Electron Density. Phys. Rev. B 1988, 37 (2), 785-789. https://doi.org/10.1103/PhysRevB.37.785.

(56) Weigend, F.; Ahlrichs, R. Balanced Basis Sets of Split Valence, Triple Zeta Valence and Quadruple Zeta Valence Quality for H to Rn: Design and Assessment of Accuracy. Phys. Chem. Chem. Phys. 2005, 7 (18), 3297-3305. https://doi.org/10.1039/b508541a.

(57) Dreuw, A.; Head-Gordon, M. Single-Reference Ab Initio Methods for the Calculation of Excited States of Large Molecules. Chem. Rev. 2005, 105 (11), 4009-4037. https://doi.org/10.1021/cr0505627.

(58) Perdew, J. P.; Burke, K.; Ernzerhof, M. Generalized Gradient Approximation Made Simple. Phys. Rev. Lett. 1996, 77 (18), 3865-3868. https://doi.org/10.1103/PhysRevLett.77.3865.

(59) Perdew, J. P.; Burke, K.; Ernzerhof, M. Erratum: Generalized Gradient Approximation Made Simple. Phys. Rev. Lett. 1997, 78 (8), 1396. https://doi.org/10.1103/PhysRevLett.78.1396.

(60) Frisch, M.; Ragazos, I. N.; Robb, M. A.; Bernhard Schlegel, H. An Evaluation of Three Direct MC-SCF Procedures. Chem. Phys. Lett. 1992, 189 (6), 524-528. https://doi.org/10.1016/00092614(92)85244-5.

(61) Andersson, K.; Malmqvist, P. Å.; Roos, B. O. Second-Order Perturbation Theory with a Complete Active Space Self-Consistent Field Reference Function. J. Chem. Phys. 1992, 96 (2), 1218-1226. https://doi.org/10.1063/1.462209.

(62) Angeli, C.; Cimiraglia, R.; Evangelisti, S.; Leininger, T.; Malrieu, J. P. Introduction of NElectron Valence States for Multireference Perturbation Theory. J. Chem. Phys. 2001, 114 (23), 10252. https://doi.org/10.1063/1.1361246.

(63) Nagao, H.; Nishino, M.; Shigeta, Y.; Soda, T.; Kitagawa, Y.; Onishi, T.; Yoshioka, Y.; Yamaguchi, K. Theoretical Studies on Effective Spin Interactions, Spin Alignments and Macroscopic Spin Tunneling in Polynuclear Manganese and Related Complexes and Their 
Mesoscopic Clusters. Coord. Chem. Rev. 2000, 198 (1), 265-295. https://doi.org/10.1016/S00108545(00)00231-9.

(64) Soda, T.; Kitagawa, Y.; Onishi, T.; Takano, Y.; Shigeta, Y.; Nagao, H.; Yoshioka, Y.; Yamaguchi, K. Ab Initio Computations of Effective Exchange Integrals for $\mathrm{H}-\mathrm{H}, \mathrm{H}-\mathrm{He}-\mathrm{H}$ and $\mathrm{Mn}_{2} \mathrm{O}_{2}$ Complex: Comparison of Broken-Symmetry Approaches. Chem. Phys. Lett. 2000, 319 (3-4), 223-230. https://doi.org/10.1016/S0009-2614(00)00166-4.

(65) Neese, F. Software Update: The ORCA Program System, Version 4.0. Wiley Interdiscip. Rev. Comput. Mol. Sci. 2018, 8 (1), 4-9. https://doi.org/10.1002/wcms.1327. 